\author{
Universidade de São Paulo \\ Instituto de Física
}

\title{
Separação de nanotubos por dispersão em solução de surfactantes: Um estudo teórico
}

\author{
Elton José Figueiredo de Carvalho
}

Orientadora: Profa. Dra. Maria Cristina dos Santos

Dissertação de mestrado apresentada ao Instituto de Física para a obtenção do título de Mestre em Ciências

Comissão examinadora:

Profa. Dra. Maria Cristina dos Santos (IFUSP)

Profa. Dra. Vera Bohomoletz Henriques (IFUSP)

Prof. Dr. Marcio Henrique Franco Bettega (UFPR)

São Paulo

2009 


\section{FICHA CATALOGRÁFICA \\ Preparada pelo Serviço de Biblioteca e Informação do Instituto de Física da Universidade de São Paulo}

Carvalho, Elton José Figueiredo de

Separação de nanotubos por dispersão em solução de surfactantes: Um estudo teórico — São Paulo, 2009.

Dissertação (Mestrado) - Universidade de São Paulo. Instituto de Física - Departamento de Física dos materiais e mecânica.

Orientadora: Profa. Dra. Maria Cristina dos Santos

Área de Concentração: Física Atômica e Molecular

Unitermos: 1. Física Molecular; 2. Solubilidade;

3. Nanopartículas; 4. Física Computacional. 
à memória da Vó Neguinha 



\section{Agradecimentos}

Existe um conjunto razoavelmente grande de pessoas e entidades que merecem minha gratidão pelo apoio em diversas etapas da realização deste trabalho. Começo agradecendo à $\operatorname{Prof}^{\mathrm{a}} \mathbf{D r}^{\mathrm{a}}$ Maria Cristina dos Santos a orientação e a paciência desde os tempos de iniciação científica. Agradeço o fomento, na forma de bolsa de estudos, ao CNPQ e à FAPESP o apoio para aquisição de equipamentos fundamentais à pesquisa.

Minha gratidão também se estende aos amigos G. T. Landi, C. E. Pellicer e C. D. Vieira por sua colaboração na revisão dos manuscritos desta dissertação. D. C. Guariento, F. M. Neto e C. E. Pellicer facilitaram minha vida fornecendo manuais e modelos de $\mathrm{LT}_{\mathrm{E} X} \mathrm{X}$.

No âmbito pessoal, devo gratidão à minha mãe pela paciência e pelo apoio ao longo desses anos de trabalho. Aos meus amigos - que não enumero para não correr o risco de deixar ninguém de fora - sempre dispostos a me acompanhar nos cafés e refeições, sem jamais deixar de me apoiar nos diversos eventos que marcaram esses anos de convivência e compartilhamento de experiências. Também agradeço aos Sifus M. Serra e F. de Paula, aos Professores Cláudio e Gilvan e aos instrutores de kungfu pelas fundamentais lições de serenidade e perseverança que me deram força para desenvolver este trabalho até sua conclusão. 



\section{Resumo}

A obtenção de amostras de nanotubos de carbono monodispersas em diâmetro e quiralidade é uma etapa importante para sua aplicação nas diversas áreas de nanotecnologia. Um recente método publicado por Arnold e colaboradores consiste em solubilizar nanotubos em água com o auxílio de surfactantes e centrifugar a solução em um gradiente de densidade. Observa-se, por medidas absorção no infravermelho, que nanotubos de diâmetro maior se encontram na região de maior densidade e aqueles de menor diâmetro, na região de densidade mais baixa. Esse resultado é oposto ao que se esperaria da densidade de cilindros ocos, que deve diminuir quando o diâmetro aumenta.

Neste trabalho buscamos explicar essa aparente discrepância através de um modelo em que os surfactantes utilizados no processo de seleção — dodecil sulfato de sódio e colato de sódio - podem ser atraídos para cavidade hidrofóbica do nanotubo e arrastar moléculas de água consigo, invertendo a relação entre densidade e diâmetro. Testamos esse modelo através de simulações de mecânica molecular e dinâmica molecular clássica. Mostramos que existe um diâmetro crítico, que depende do surfactante, a partir do qual ele passa a ter mais afinidade com o interior da cavidade do nanotubo que com sua superfície externa. Mostramos também a existência de um diâmetro ótimo, em que a afinidade do surfactante com o interior do nanotubo é máxima.

Simulações de dinâmica molecular acusaram a existência de uma força que atrai moléculas de surfactante para o interior do tubo e lá as aprisiona. Moléculas de água aderidas ao surfactante também são arrastadas para o interior do tubo. Através de dinâmica molecular também notamos que mesmo em solução aquosa há preferência de surfactantes maiores em tubos maiores.

Calculamos a densidade de nanotubos vazios, preenchidos somente com água e preenchidos com água e surfactante. Na ausência de uma camada de surfactante encapsulando os nanotubos, mostramos que não há separação por diâmetro em gradiente de densidade se os nanotubos estiverem preenchidos. A existência de uma camada de surfactante viabiliza a separação por diâmetro de nanotubos preenchidos e explica a distribuição crescente de diâmetros em função da densidade. 


\section{Abstract}

Obtaining carbon nanotube samples which are monodisperse in diameter and chirality is an important step for its successful application in various nanotechnology areas. A recent procedure published by Arnold and collaborators consists in solubulizing carbon nanotubes in water with the help of surfactants and centrifuging the resulting solution in a density gradient. It is then observed, via infrared absorbance spectra, that larger diameter nanotubes are found in the larger density area while those smaller in diameter are found in lower density areas. This result is opposite to what one would expect from empty cylinders, in which the density decreases with increasing diameter.

In this work we seek explanation to this discrepancy through a model in which surfactants used in the selection process - sodium dodecyl sulfate and sodium cholate - can be attracted towards the nanotube's hydrophobic cavity and drag water molecules with them, thus inverting the density/diameter relationship. We tested this model via molecular mechanics and classical dynamics simulations, showing that there is a critical diameter, which depends on the surfactant, at which the binding energy between the surfactant and the tube cavity exceeds that with the tube's outer surface. We also obtained an optimal diameter, which maximizes surfactant's binding energy with the tube interior.

Molecular dynamics simulations showed the presence of a force which attracts surfactant molecules towards the nanotube cage and imprisons it there. Water molecules adhered to the surfactant are also dragged to the cage. We also noted, via molecular dynamics, that even in aqueous solutions larger surfactant molecules are preferred inside larger diameter tubes.

We calculated the density of nanotubes in three conditions: empty, filled with water and filled with a mixture of water and surfactants. In the absence of a surfactant layer encapsulating the tubes we show that there is no separation by diameter via density gradient of the tubes are filled. The surfactant layer makes possible density gradient separation of nanotubes by diameter if the tubes are filled and explains the density increase with increasing diameter. 


\section{Sumário}

Resumo vii

Abstract viii

\begin{tabular}{lll}
\hline & Introdução & 1
\end{tabular}

2 Carbono 5

2.1 Estrutura eletrônica e hibridização . . . . . . . . . . . . 5

2.2 Materiais de carbono $\ldots \ldots \ldots \ldots$. . . . . . . . . . . . 7

$2.2 .1 \quad$ Diamante . . . . . . . . . . . . . . . . . . . 7

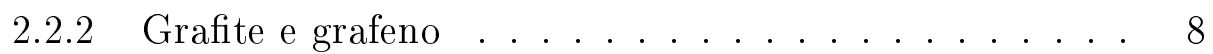

2.2 .3 Fulerenos . . . . . . . . . . . . . . . . . . . 10

2.3 Nanotubos de Carbono . . . . . . . . . . . . . . . . . . . . . . . 11

2.3 .1 Propriedades geométricas e eletrônicas . . . . . . . . . 11

$2.3 .2 \quad$ Métodos experimentais de síntese . . . . . . . . . . . . 14

2.3 .3 Técnicas de separação e isolamento . . . . . . . . . . . 15

$2.3 .4 \quad$ O papel dos surfactantes . . . . . . . . . . . . . 15

$\begin{array}{lll}3 & \text { Métodos } & 17\end{array}$

3.1 Parâmetros de mecânica molecular . . . . . . . . . . . . . 17

3.2 Protocolo de solvatação . . . . . . . . . . . . . . . . . . . . . 18

4 Interação entre nanotubos e surfactantes 21

4.1 Modelagem dos nanotubos e surfactantes . . . . . . . . . . . . 22

4.2 Energia de interação no vácuo . . . . . . . . . . . . . . . . . 23

4.3 Interação em meio aquoso $\ldots \ldots \ldots$. . . . . . . . . . . . 26

5 Dinâmica molecular $\quad 29$

5.1 Dinâmica molecular em vácuo . . . . . . . . . . . . . . . . . . 29

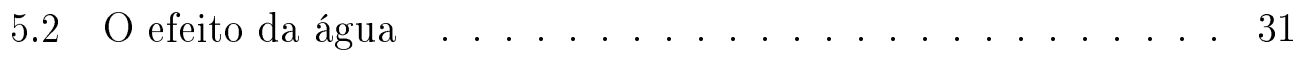

ix 
6 Densidade $\quad 35$

6.1 Densidade no estado sólido . . . . . . . . . . . . . . . . . . . . 36

6.2 Densidade em solução . . . . . . . . . . . . . . . . . . . . . . 39

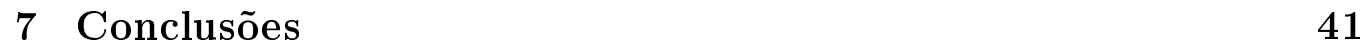

\begin{tabular}{|ll}
\hline A Mecânica Molecular: Teoria & 43
\end{tabular}

A.1 Campos de força . . . . . . . . . . . . . . . . . . 45

A.2 Otimização de geometria . . . . . . . . . . . . . . . . . . . 49

B Dinâmica Molecular: Teoria $\quad 51$

B.1 Mantendo a temperatura constante . . . . . . . . . . . . . 53 


\section{Lista de Figuras}

1.1 Separação de nanotubos por diâmetro . . . . . . . . . . . . . . 2

2.1 Célula unitária do diamante . . . . . . . . . . . . . . . . . . . 7

2.2 Estrutura do grafite . . . . . . . . . . . . . . . . . . 8

$2.3 \quad$ Estrutura de bandas do grafeno . . . . . . . . . . . . . . . . . . 9

2.4 Grafeno como gabarito de estruturas de carbono . . . . . . . . 10

$2.5 \quad$ Estrutura do $\mathrm{C}_{60} \quad \ldots \ldots \ldots \ldots \ldots \ldots$

2.6 Propriedades geométricas de um nanotubo . . . . . . . . . . 12

2.7 Nanotubos de diferentes quiralidades . . . . . . . . . . . . . . . . 12

2.8 Estruturas de bandas do grafeno . . . . . . . . . . . . . . . . . 13

4.1 Estruturas dos três surfactantes tratados neste trabalho. . . . 21

4.2 Configurações de nanotubos e surfactantes . . . . . . . . . . . 23

4.3 Energia de interação do sistema nanotubo-surfactante . . . . . 24

4.4 Efeito da água na interação entre nanotubo e surfactante . . . 27

5.1 Passos de dinâmica molecular em vácuo . . . . . . . . . . . . . 30

5.2 Energia potencial: dinâmica molecular $(14,0)$. . . . . . . . . 31

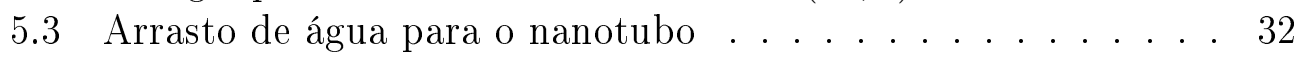

5.4 Dinâmica: Água na entrada do nanotubo . . . . . . . . . . . . 34

6.1 Esquema do cálculo da densidade . . . . . . . . . . . . . . 35

6.2 Caixa de simulação para obtenção do número ótimo de moléculas de água no interior do tubo . . . . . . . . . . . . 36

6.3 Exemplo de feixe hexagonal de nanotubos . . . . . . . . . 37

6.4 Densidade dos nanotubos simulada em estado sólido. . . . . . 38

6.5 Densidade dos nanotubos calculada com a presença de uma camada de surfactante . . . . . . . . . . . . 44 40

A.1 Tipos de torção e inversão . . . . . . . . . . . . . . . . . . . 48 



\section{Capítulo 1}

\section{Introdução}

Nanotubos de carbono (abreviados como CNT) são moléculas longas e finas cuja geometria pode ser entendida como se uma única folha da estrutura do grafite - conhecida como grafeno - fosse enrolada na foma de um cilindro ${ }^{1}$. Devido às diversas formas com que essas folhas podem ser enroladas, é possível imaginar nanotubos com diversas propriedades geométricas, como, por exemplo, diâmetro e orientação das fitas de anéis aromáticos, cada um deles com propriedades eletrônicas distintas e dependentes da geometria. Mais detalhes das relações entre a estrutura e essas propriedades são discutidos no Capítulo 2 ,

Devido a essas propriedades únicas, os nanotubos têm grande potencial de aplicação em diversas áreas ${ }^{2}$, incluindo reforço mecânico de materiais ${ }^{3}$, eletrônica molecular, na forma de transistores moleculares ${ }^{415}$ ou condutores, geração e armazenamento de energia, aumentando a eficiência de células solares ${ }^{6}$, baterias de lítio ${ }^{7} \mathrm{e}$ armazenamento de hidrogênio para uso em células a combustível ${ }^{8}$, sensores químicos ${ }^{9[10}$ — inclusive detectores de armas químicas ${ }^{11}$. Nanotubos também têm potencial para aplicações em medicina como no tratamento de câncer ${ }^{12}$ e em microscopia, melhorando a resolução de microscópios de força atômica ${ }^{13}$. 15 .

Muitas dessas aplicações exigem nanotubos com uma certa propriedade mecânica ou eletrônica bem definida, como ser semicondutor no caso de transistores moleculares, ou ser condutor de eletricidade, no caso dos microscópios

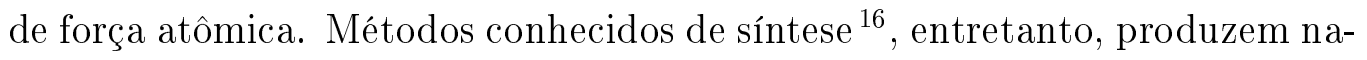
notubos com variadas geometrias, distribuídas em largos intervalos de diâmetro e quiralidade, de modo que uma amostra de nanotubos recém-sintetizados pode conter tanto nanotubos condutores quanto semicondutores, em diferentes proporções, dificultando sua aplicação direta em alguns campos.

Para contornar esse tipo de empecilho, técnicas de separação de nanotubos por diâmetro e estrutura eletrônica foram recentemente desenvolvidas ${ }^{17}$ 
e chama a atenção o processo não destrutivo proposto por Arnold e colaboradores ${ }^{18}$ em que se dispersa feixes de nanotubos em soluções de água e surfactante. A subseqüente ultracentrifugação em um gradiente de densidade distribui CNTs de diferentes diâmetros de acordo com sua densidade no tubo da centrífuga, como mostra a Figura 1.1 com resultados de absorção no infravermelho.

a

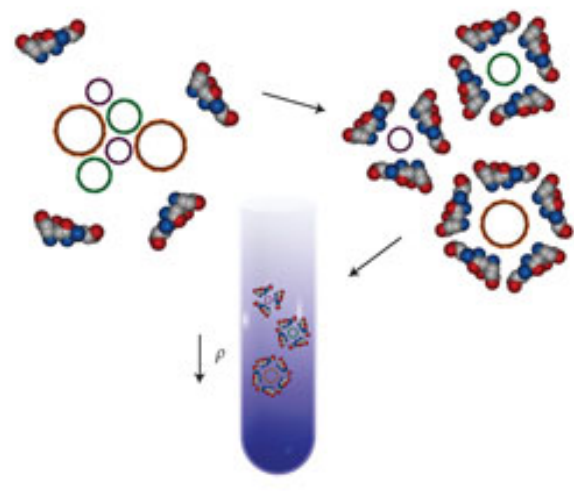

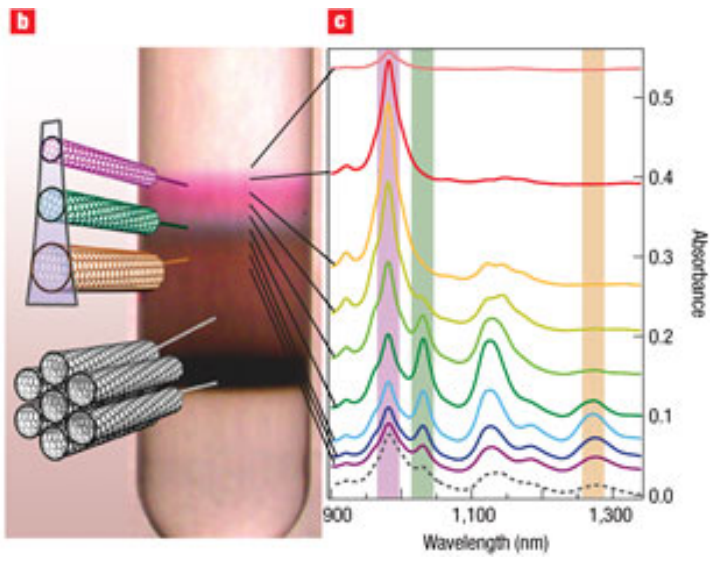

Figura 1.1: Separação de nanotubos por diâmetro. a. Proposta de Arnold et al. para o fenômeno de seleção. b. Fotografia do tubo da centrífuga com amostras de CNT após o processo. c. Espectro de absorção da amostra, mostrando que nanotubos de maior diâmetro se encontram em regiões de maior densidade. Figura extraída do artigo de Arnold et al.18

A possibilidade desse processo de seleção ser realizado em cascata, repetindo o processo iterativamente e sua escalabilidade são comentadas por A. Rinzler ${ }^{19}$, que também traz à tona o fato surpreendente de os nanotubos se distribuírem "na direção oposta do que seria esperado com base na relação entre a densidade de nanotubos puros e seu diâmetro".

De fato, nanotubos de carbono de parede simples são cilindros ocos e sua massa é proporcional à área de sua superfície:

$$
m \sim \pi D \times L
$$

onde $D$ é o diâmetro do nanotubo e $L$ seu comprimento (omitimos, por simplicidade, a densidade superficial de uma folha de grafeno). Ao calcularmos a densidade de um nanotubo, dividimos a massa, proporcional à área, pelo volume:

$$
\rho=\frac{m}{V} \sim \frac{\pi D \times L}{\pi(D / 2)^{2} \times L}=\frac{4}{D} .
$$

Portanto, a densidade de um nanotubo de carbono vazio é inversamente proporcional ao seu diâmetro. 
Este trabalho foi dedicado ao estudo da interação entre surfactantes e nanotubos em água. Com isso, encontramos um mecanismo capaz de conciliar essa aparente contradição: surfactantes podem ser atraídos para o interior dos nanotubos que, ao serem preenchidos, podem ter alterada a relação entre diâmetro e densidade.

A possibilidade de surfactantes entrarem em nanotubos é restrita por limitações geométricas: moléculas de surfactantes eventualmente não "cabem" em CNTs de diâmetro muito pequeno. Com isso é também possível propor uma explicação para a observação de Arnold ${ }^{18}$, segundo a qual misturas de diferentes surfactantes apresentam eficiência variada em separar tubos sintetizados por diferentes métodos e, portanto, com diferentes diâmetros.

Testamos esse modelo através de mecânica molecular e dinâmica molecular clássica. Calculamos a energia potencial do sistema surfactante-CNT em diversas configurações, em vácuo e na presença de moléculas de água. Mostramos quais os requisitos para um surfactante ter como posição de equilíbrio o interior do nanotubo. Desenvolvemos um modelo para a camada de surfactante no exterior do CNT e com ele calculamos a relação entre a densidade e o diâmetro, obtendo excelentes resultados.

Para apresentar esse trabalho, começamos no Capítulo 2 com um resumo sobre as propriedades de materiais de carbono e as relações entre as propriedades e a estrutura de nanotubos de carbono. No Capítulo 3, descrevemos nossas ferramentas e protocolos que adotamos para realizar as simulações. O Capítulo 4 inicia com a descrição dos surfactantes e nanotubos estudados e então relata os cálculos de energia potencial dos sistemas surfactante-CNT em diversas configurações, na presença e na ausência de moléculas de água. O Capítulo 5 versa sobre as simulações de dinâmica molecular que realizamos para testar se moléculas de surfactante podem entrar no nanotubo ou se há uma barreira energética que impeça esse deslocamento. Mostramos nesse capítulo que, além da molécula de surfactante ser atraída para a cavidade do nanotubo de diâmetro adequado, é capaz de arrastar moléculas de água consigo. No Capítulo 6 revelamos o modelo que leva em conta uma camada de surfactante em torno do nanotubo para obter a relação entre densidade e diâmetro em solução. Resumimos nossas conclusões no Capítulo 7 Finalmente, apresentamos os fundamentos dos algoritmos e parâmetros envolvidos em simulações de mecânica molecular e dinâmica molecular clássica. 



\section{Capítulo 2}

\section{Carbono}

Carbono é um elemento químico versátil quanto à sua capacidade de formar ligações químicas. Essa é uma das razões porque toma parte na composição de substâncias fundamentais à manutenção da vida. Sua estrutura eletrônica permite que se ligue com dois, três ou quatro átomos em diferentes configurações geométricas. Carbono puro é conhecido em três formas alotrópicas: grafite, diamante e fulerita (cristais de fulerenos $\mathrm{C}_{60}$ ), com propriedades muito diferentes uma das outras.

Neste capítulo vamos explorar os fenômenos eletrônicos que demonstram a versatilidade ao carbono. Em seguida, descrevemos sucintamente três estruturas de carbono: o diamante, o grafite e os fulerenos. Finalmente, descreveremos em algum detalhe as propriedades dos nanotubos de carbono, foco dos estudos neste trabalho.

\subsection{Estrutura eletrônica e hibridização}

Os seis elétrons do carbono se distribuem em duas camadas formando a configuração $1 s^{2} 2 s^{2} 2 p^{2}$ de modo que dois elétrons desemparelhados dos orbitais $p$ estão disponíveis para fazer ligações covalentes. Entretanto, como a energia necessária para promover um dos elétrons do orbital $2 s$ para o $2 p$ é pequena ${ }^{16}$, a energia proveniente de uma ligação química permite que o átomo de carbono atinja o estado excitado $1 s^{2} 2 s^{1} 2 p^{3}$, colocando quatro elétrons desemparelhados à disposição de ligações químicas.

Existem três formas de combinar linearmente os orbitais $|2 s\rangle$ e $|2 p\rangle$ de modo a obtermos orbitais ortogonais entre si: combinando um orbital $|2 s\rangle$ com um, dois ou três orbitais $\left|2 p_{i}\right\rangle$. A combinação do orbital $|2 s\rangle$ com um orbital $|2 p\rangle$ dá origem à chamada hibridização sp, caso em que se formam os orbitais 


$$
\begin{aligned}
& \left|s p_{+}\right\rangle=\frac{1}{\sqrt{2}}\left\{|2 s\rangle+\left|2 p_{x}\right\rangle\right\} \mathrm{e} \\
& \left|s p_{-}\right\rangle=\frac{1}{\sqrt{2}}\left\{|2 s\rangle-\left|2 p_{x}\right\rangle\right\},
\end{aligned}
$$

por exemplo. Esses dois orbitais são assimétricos em relação à reflexão no eixo $x$, sendo o $\left|s p_{+}\right\rangle$mais alongado na direção positiva do eixo $x$ e o $\left|s p_{-}\right\rangle$na direção negativa. Essa assimetria fornece uma possibilidade de combinação mais intensa da função de onda do elétron desemparelhado com um elétron de um átomo vizinho, reduzindo a energia do sistema e formando uma ligação covalente.

A ligação entre dois átomos de carbono apresentando hibridização $s p$ forma uma ligação tripla. O orbital $\left|s p_{+}\right\rangle$de um átomo se combina com o orbital $\left|s p_{-}\right\rangle$de seu vizinho, formando uma ligação $\sigma$. Já os orbitais $\left|2 p_{y}\right\rangle$ desses dois átomos se combinam formando um orbital molecular com um plano nodal, chamado de orbital $\pi$. O mesmo acontece com os orbitais $\left|2 p_{z}\right\rangle$, de modo que três orbitais de cada átomo se estão envolvidos na ligação. Um exemplo de átomo de carbono neste estádo é encontrado da molécula de acetileno $\left(\mathrm{C}_{2} \mathrm{H}_{2}\right)$.

É possível também combinar o orbital $|2 s\rangle$ com dois orbitais $\left|2 p_{i}\right\rangle$, formando três novos orbitais, caso em que temos a hibridização $s p^{2}$. Os três orbitais $\left|s p^{2}\right\rangle$ são combinações lineares de três orbitais que compartilham um plano de simetria de reflexão, então devem herdar essa propriedade. Como vimos, orbitais do tipo $s p^{n}$ são alongados em uma direção, portanto os três orbitais $\left|s p_{i}^{2}\right\rangle$ devem ser ortogonais entre si, alongados em três direções diferentes e coplanares. Para que essas condições sejam obedecidas as três direções devem se distribuir formando ângulos de $120^{\circ}$ entre si. Com isso, formam-se os orbitais

$$
\begin{aligned}
& \left|s p_{a}^{2}\right\rangle=\frac{1}{\sqrt{3}}|2 s\rangle-\frac{2}{\sqrt{6}}\left|2 p_{y}\right\rangle, \\
& \left|s p_{b}^{2}\right\rangle=\frac{1}{\sqrt{3}}|2 s\rangle+\frac{1}{\sqrt{2}}\left|2 p_{x}\right\rangle+\frac{1}{\sqrt{6}}\left|2 p_{y}\right\rangle \mathrm{e} \\
& \left|s p_{c}^{2}\right\rangle=\frac{1}{\sqrt{3}}|2 s\rangle-\frac{1}{\sqrt{2}}\left|2 p_{x}\right\rangle+\frac{1}{\sqrt{6}}\left|2 p_{y}\right\rangle .
\end{aligned}
$$

Átomos de carbono $s p^{2}$ podem fazer três ligações $\sigma$ coplanares e o orbital $\left|2 p_{z}\right\rangle$ permanece disponível para realizar ligações $\pi$. É neste estado de hibridização que se encontram os átomos de carbono no grafite, fulerenos e nanotubos e na molécula de etileno $\left(\mathrm{C}_{2} \mathrm{H}_{4}\right)$. 
O carbono forma estruturas tetragonais com quatro ligações $\sigma$ quando seu orbital $|2 s\rangle$ se combina com os três orbitais $\left|2 p_{i}\right\rangle$ formando os orbitais

$$
\begin{aligned}
& \left|s p_{a}^{3}\right\rangle=\frac{1}{2}\left\{|2 s\rangle+\left|2 p_{x}\right\rangle+\left|2 p_{y}\right\rangle+\left|2 p_{z}\right\rangle\right\}, \\
& \left|s p_{b}^{3}\right\rangle=\frac{1}{2}\left\{|2 s\rangle-\left|2 p_{x}\right\rangle-\left|2 p_{y}\right\rangle+\left|2 p_{z}\right\rangle\right\}, \\
& \left|s p_{c}^{3}\right\rangle=\frac{1}{2}\left\{|2 s\rangle-\left|2 p_{x}\right\rangle+\left|2 p_{y}\right\rangle-\left|2 p_{z}\right\rangle\right\} \mathrm{e} \\
& \left|s p_{d}^{3}\right\rangle=\frac{1}{2}\left\{|2 s\rangle+\left|2 p_{x}\right\rangle-\left|2 p_{y}\right\rangle-\left|2 p_{z}\right\rangle\right\},
\end{aligned}
$$

dando origem à hibridização $s p^{3}$. Neste estado se encontra o átomo de carbono da molécula de metano $\left(\mathrm{CH}_{4}\right)$ e do diamante, por exemplo.

\subsection{Materiais de carbono}

As diversas formas de hibridização do carbono permitem que os átomos formem estruturas lineares $(s p)$, planares $\left(s p^{2}\right)$ ou tetraédricas $\left(s p^{3}\right)$. Dessa forma, existe certa variedade de estruturas formadas apenas por átomos desse elemento.

\subsubsection{Diamante}

Um cristal formado de átomos de carbono $s p^{3}$ ligados de forma tetraédrica (vide Fig. 2.1) é o material mais duro conhecido, chamado de diamante.

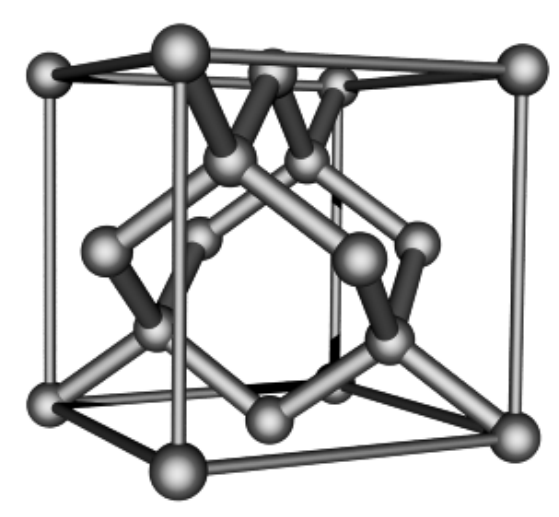

Figura 2.1: Célula unitária do diamante É possível observar a estrutura cúbica de face centrada que forma o diamante, com átomos nos vértices e nos centros das faces. 
Transparente, apresenta um gap óptico de $5.4 \mathrm{eV} 20$. Outra propriedade excepcional do diamante oriunda de sua rígida estrutura tetraédrica é a condutividade térmica superior a $20 \mathrm{~W} / \mathrm{cm} \cdot \mathrm{K}^{21}$, colocando entre os melhores condutores térmicos à temperatura ambiente.

\subsubsection{Grafite e grafeno}

Um átomo de carbono $s p^{2}$ pode formar três ligações coplanares. Associar diversos átomos nessa condição leva à formação de estruturas planares de anéis hexagonais ${ }^{22}$, semelhantes a colméias de abelha ou telas de galinheiro, como na Fig. 2.2, com cada átomo de carbono ligado a três vizinhos por ligações covalentes. Esses planos são chamados de grafenos e despertam grande interesse por suas propriedades ${ }^{23}$, como a maior resistência mecânica dentre as substâncias conhecidas 2425 .

Folhas de grafeno se apresentam "empilhadas" no grafite, formando camadas que podem deslizar facilmente umas sobre as outras, ligadas fracamente por forças de van der Waals. Por isso o grafite é amplamente utilizado como lubrificante. Sua baixa dureza também lhe confere a aplicação que lhe rendeu seu nome: a escrita.

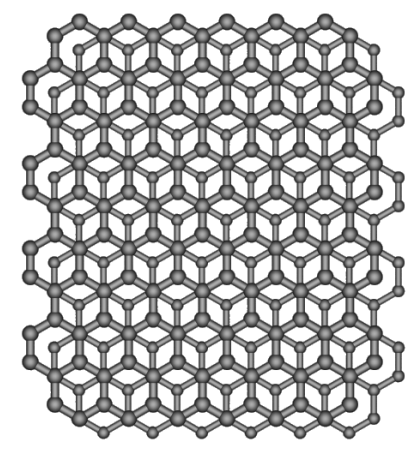

(a) Vista do topo

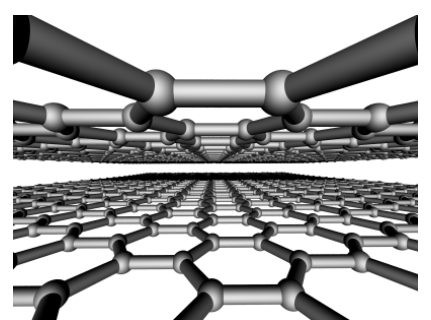

(b) Vista de frente

Figura 2.2: Estrutura do grafite. Em (a), destacamos o alinhamento entre os átomos de camadas vizinhas.

\section{Estrutura eletrônica}

Uma vez que uma folha de grafeno é um cristal bidimensional com dois átomos na base, podemos calcular as bandas de energia através do método de tight binding ${ }^{16 \mid 26}$, obtendo, para as bandas $\pi$, as energias

$$
E(\mathbf{k})=\frac{\epsilon_{2 p}+t w(\mathbf{k})}{1+s w(\mathbf{k})}
$$


para a banda $\pi$ ligante $\mathrm{e}$

$$
E^{*}(\mathbf{k})=\frac{\epsilon_{2 p}-t w(\mathbf{k})}{1-s w(\mathbf{k})}
$$

para a banda $\pi$ antiligante. Nessas expressões,

$$
s=\left\langle\phi_{A}\left(\mathbf{r}_{A}\right) \mid \phi_{B}\left(\mathbf{r}_{B}\right)\right\rangle=0,0129
$$

é a integral de sobreposição entre os dois átomos da base,

$$
t=\left\langle\phi_{A}\left(\mathbf{r}_{A}\right)|\mathcal{H}| \phi_{B}\left(\mathbf{r}_{B}\right)\right\rangle=-0,303 \mathrm{eV}
$$

é a integral de transferência entre os dois átomos e

$$
w(\mathbf{k})=\sqrt{1+4 \cos \frac{\sqrt{3} k_{x} a}{2} \cos \frac{k_{y} a}{2}+4 \cos ^{2} \frac{k_{y} a}{2}}
$$

é um fator de forma relacionado ao fato de termos dois átomos na base da estrutura cristalina ${ }^{27}$. Isso resulta nas bandas de energia do grafeno (Fig. 2.3). Nela vemos que o gap somente se anula nos vértices da primeira zona de Brillouin, hexagonal. Por isso, uma folha de grafeno é classificada como um semicondutor de gap nulo.

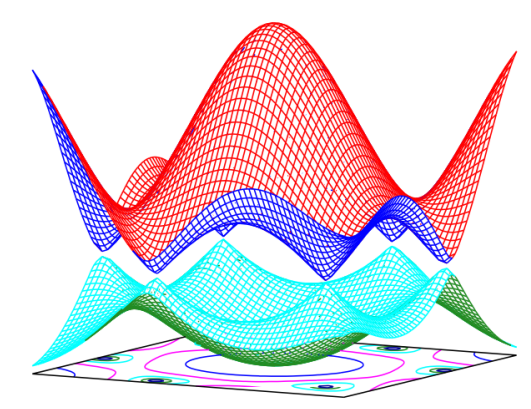

Figura 2.3: Estrutura de bandas do grafeno. Representamos a mais alta banda de valência e a mais baixa banda de condução do grafeno calculada pelo método de tight binding $16 \mid 26$.

Quando as folhas de grafeno se empilham para formar o grafite, as interações de van der Waals entre elas deslocam as bandas de valência e de condução, de modo que elas se sobreponham, fazendo com que haja uma ocupação de elétrons na banda de condução e de buracos na banda de valência. Com isso, o grafite passa a ter o comportamento de um semimetal.

O grafeno pode ser entendido como um gabarito para diversas estruturas baseadas no carbono $s p^{2}$, como fulerenos e nanotubos de carbono. A Fig 2.4 mostra como regiões de uma folha de grafeno podem dar origem a essas estruturas. 


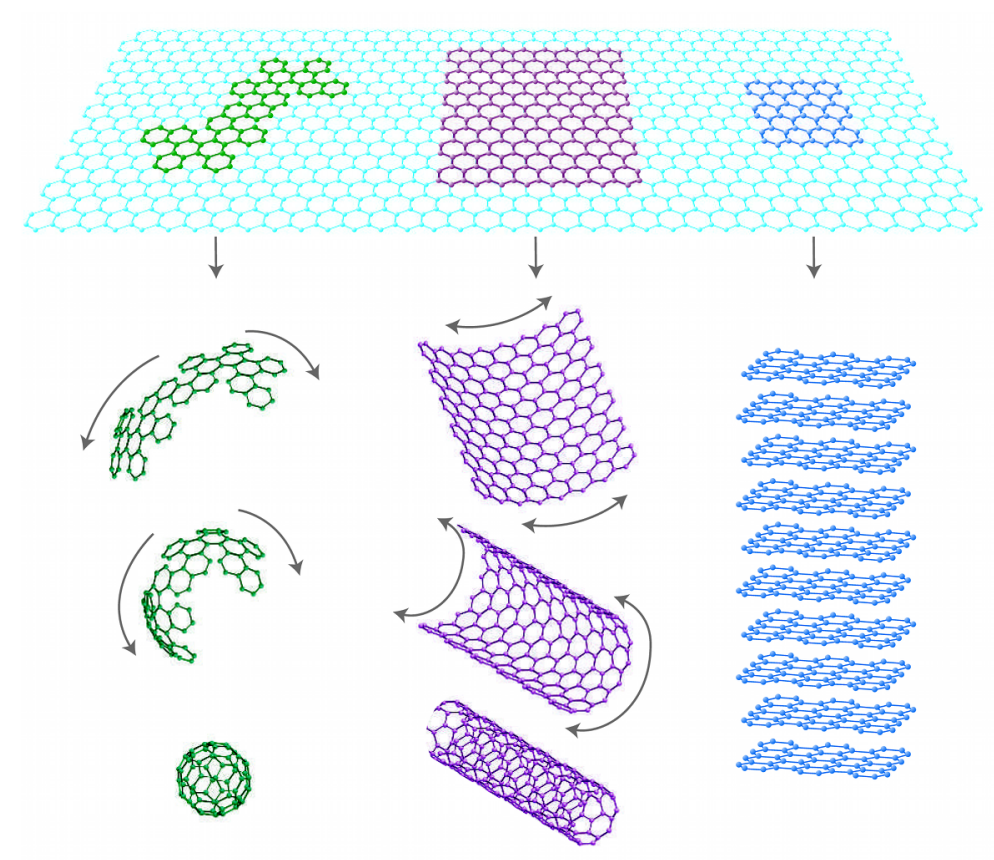

Figura 2.4: Grafeno como gabarito de estruturas de carbono. Esta figura do artigo de Geim e Novoselov ${ }^{23}$ mostra como regiões de uma folha de grafeno bidimensional podem ser enroladas para formar fulerenos de dimensão zero ou nanotubos unidimensionais ou empilhadas formando grafite tridimensional.

\subsubsection{Fulerenos}

Em 1985, "durante experimentos para compreender o mecanismo de formação de longas cadeias carbônicas em ambientes estelares", Kroto e colaboradores ${ }^{[28}$ se depararam com um aglomerado estável de 60 átomos de carbono. Propuseram uma estrutura altamente simétrica (Fig. 2.5) similar à de estruturas geodésicas $^{29}$ projetadas pelo arquiteto R. Buckminster Fuller. Por isso sugeriram o nome de Buckminsterfulereno para essa estrutura.

Moléculas semelhantes, com variadas quantidades de átomos de carbono, passaram a ser estudadas sob o nome coletivo de fulerenos. Esferóides, essas moléculas são formadas por átomos de carbono $s p^{2}$ fazendo três ligações cada, como no grafite. Entretanto, pentágonos se inserem na rede hexagonal, fazendo com que a estrutura se feche em um poliedro.

Dentre as diversas propriedades de interesse, destaca-se a de poderem acomodar átomos em seu interior, especialmente nitrogênio ou boro para uso em computadores quânticos ${ }^{30}$. Podem também ser dopados com esses elementos para formarem retificadores moleculares 31 [33. 


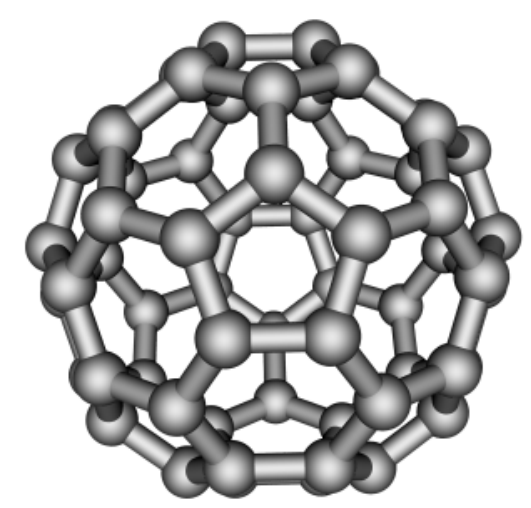

Figura 2.5: Estrutura do fulereno $\mathbf{C}_{60}$. Note as faces pentagonais que lhe conferem a curvatura.

\subsection{Nanotubos de Carbono}

Nanotubos de carbono são cilindros ocos de carbono, com diâmetro em torno de $1 \mathrm{~nm}$ e comprimento que pode variar de algumas dezenas de nanômetros até alguns milímetros ${ }^{34}$. Essas estruturas receberam destaque após serem sintetizadas por Sumio Iijima ${ }^{\frac{35}{5}}$ ao fazer saltar um arco elétrico entre duas pontas de grafite, um processo semelhante ao utilizado para sintetizar fulerenos ${ }^{28}$. Inicialmente, os nanotubos foram sintetizados como tubos de paredes múltiplas ${ }^{36}$ e em 1993 Iijima descobriu ${ }^{11}$ um método para gerar CNTs cuja parede é formada por apenas uma camada de átomos de carbono.

Esses nanotubos de carbono de parede simples (conhecidos como SWNT) despertam bastante interesse devido à sua grande resistência mecânica e flexibilidade e a suas propriedades eletrônicas dependentes da geometria ${ }^{16}$. Essa característica permite que nanotubos de carbono sejam metálicos ou semicondutores, tornando-os bastante úteis em eletrônica molecular, microscopia e em diversas áreas de aplicação.

\subsubsection{Propriedades geométricas e eletrônicas}

Uma vez que o SWNT pode ser entendido como uma única folha de grafeno enrolada, ele compartilha com essa estrutura algumas de suas propriedades eletrônicas. Vemos na Fig. 2.6 uma folha de grafeno esquematizada com seus vetores da rede $\mathbf{a}_{1}$ e $\mathbf{a}_{2}$.

Quando uma folha de grafeno é enrolada, define-se uma condição cíclica de contorno, de modo que o sistema passa a ser finito na direção do chamado vetor quiral $\mathbf{C}_{\mathbf{h}}=n \mathbf{a}_{\mathbf{1}}+m \mathbf{a}_{\mathbf{2}}$ do nanotubo. Esse vetor, no nanotubo enrolado, representa a circunferência do cilindro. As coordenadas $(n, m)$ do vetor quiral 


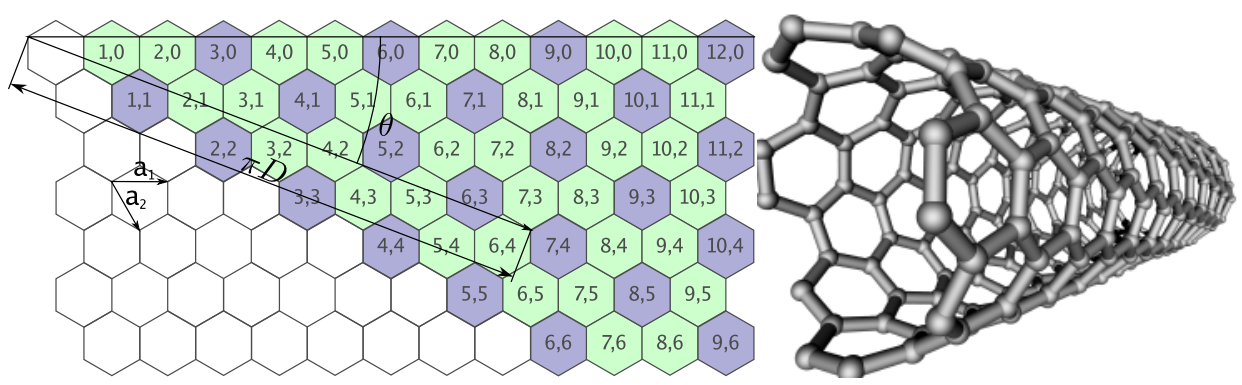

Figura 2.6: Propriedades geométricas de um nanotubo de carbono. $\mathrm{O}(7,4)(\grave{a}$ direita) é um nanotubo metálico. $\theta$ : ângulo quiral; $D$ : Diâmetro. Hexágonos verdes (mais claros) nanotubos semicondutores. Hexágonos azuis (mais escuros): nanotubos metálicos.

servem para indexar os nanotubos, por conterem informações sobre seu raio e sua quiralidade.

As propriedades geométricas mais importantes de um nanotubo são seu diâmetro $D$ e o ângulo quiral $\theta$. Calculamos o diâmetro a partir do comprimento do vetor quiral:

$$
D=\frac{\left|\mathbf{C}_{\mathbf{h}}\right|}{\pi}=\frac{\sqrt{3} a_{C-C}}{\pi} \sqrt{n^{2}+m^{2}+n m},
$$

onde $a_{C-C}$ é o comprimento da ligação entre carbonos e vale $1,42 \AA$. Obtemos o ângulo quiral através da expressão

$$
\cos \theta=\frac{2 n+m}{\sqrt{n^{2}+m^{2}+n m}} .
$$

Essas duas expressões vêm de relações de geometria plana utilizando a base não ortogonal de vetores $\mathbf{a}_{\mathbf{1}} \mathrm{e} \mathbf{\mathbf { a } _ { 2 }}$, que apresentam um ângulo de $60^{\circ}$ entre si.

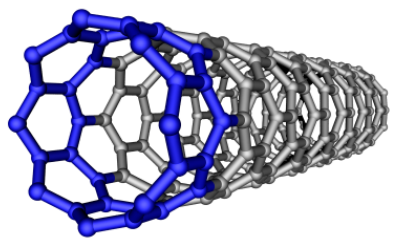

(a) $(8,0)$, zigzag

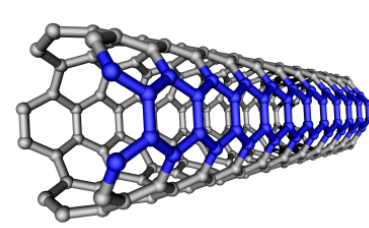

(b) $(5,5)$, armchair

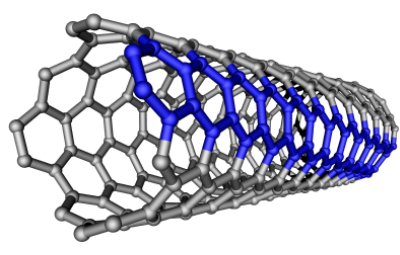

(c) $(7,4)$, quiral

Figura 2.7: Exemplos de nanotubos de diferentes quiralidades. As fileiras de anéis aromáticos destacadas em azul mostram o efeito da quiralidade.

Com base no ângulo quiral, podemos definir três grupos de nanotubos: os aquirais zigzag $(n, 0)$ e armchair $(n, n)$ e os tubos quirais $(n, m)$, com $m \neq 0$ 
e $m \neq n$. Os primeiros são chamados de aquirais pois as fileiras de anéis aromáticos se fecham formando uma circunferência (zigzag, Fig. 2.7(a)) ou são paralelos ao eixo do tubo (armchair, Fig. 2.7(b)). Nos demais nanotubos, cada fileira de anéis aromáticos forma uma hélice ao redor do eixo do tubo.

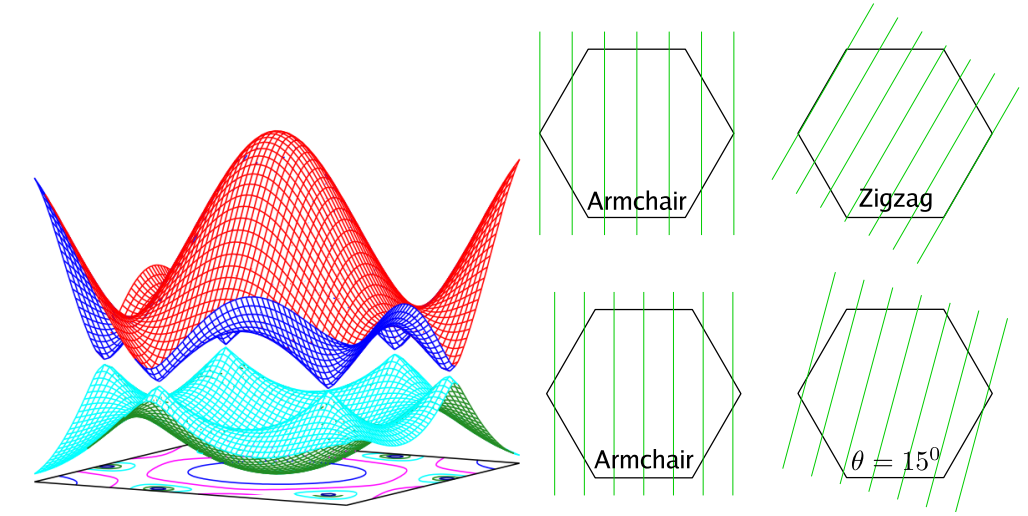

Figura 2.8: Estrutura de bandas do grafeno. Observamos que as bandas de valência condução só se tocam nos vértices da zona de Brillouin. Direita: Condições de contorno para quatro nanotubos. Nanotubos tipo zigzag são metálicos. Nanotubos armchair podem ser metálicos (acima) ou semicondutores (abaixo), dependendo do diâmetro. O mesmo vale para outros ângulos quirais.

Uma vez que o nanotubo de carbono apresenta condições cíclicas de contorno na direção do vetor quiral - consistindo, portanto, em um sistema finito - somente alguns vetores de onda $\mathbf{k}$ serão acessíveis aos elétrons: aqueles que apresentarem um número inteiro de comprimentos de onda ao longo da circunferência do tubo. Essas condições de contorno levam ao surgimento de linhas de estados acessíveis, perpendiculares ao vetor quiral do nanotubo e cuja distância entre si no espaço recíproco é inversamente proporcional ao diâmetro do nanotubo. Somente se essas linhas interceptarem algum vértice da zona de Brillouin, onde o gap é nulo, teremos um nanotubo metálico, em vez de semicondutor. É possível mostrar ${ }^{16}$ que essa intersecção ocorre quando $(n-m)$ é múltiplo de 3 , por isso a natureza metálica ou semicondutora dos nanotubos depende dos índices $n$ e $m$.

Já que os vetores $\mathbf{k}$ acessíveis aos elétrons, antes distribuídos por toda a zona de Brillouin, se acumulam nessas linhas de estados acessíveis, a densidade de estados também sofre mudanças, formando picos nos níveis de energia correspondentes aos estados acessíveis. Esses picos são conhecidos como singularidades de van Hove e são característicos de sistemas periódicos unidimensionais. Os níveis de energia em que se encontram as singularidades de van Hove variam de acordo com a geometria do nanotubo e desempenham 
um papel fundamental na identificação de nanotubos por fotoluminescência.

Dessa forma, a seleção de nanotubos de acordo com suas propriedades geométricas é uma etapa importante na aplicabilidade dessas estruturas em dispositivos que exijam propriedades eletrônicas bem definidas, como microscópios de força atômica que exigem nanotubos metálicos ou retificadores moleculares, que dependem de nanotubos semicondutores.

\subsubsection{Métodos experimentais de síntese}

Existe um conjunto de técnicas para síntese de nanotubos de carbono de parede simples que consistem essencialmente em depositar partículas de carbono sobre um substrato e purificar esse depósito, separando os nanotubos de fulerenos, nanopartículas metálicas, fibras etc. $\underline{16}$

Vamos mencionar os dois métodos de síntese de nanotubos utilizados por Arnold e colaboradores $\frac{18}{18}$ : abrasão a laser e CoMoCAT 37 .

O processo a laser, que produz nanotubos de $11 \AA$ a $16 \AA$ de diâmetro consiste em bombardear com pulsos de laser de neodímio-ítrio-alumínio uma pastilha de grafite impregnada com 1,2\% de átomos de níquel e cobalto em um forno cilíndrico mantido a $1200^{\circ} \mathrm{C}$. Pelo forno passa um fluxo de argônio que varre o vapor de carbono até um coletor de cobre resfriado a água. Sobre esse coletor forma-se um "feltro" de feixes de nanotubos de cerca de $100 \mu \mathrm{m}$ de comprimento $\frac{16}{}$.

Um processo mais recente, conhecido como CoMoCAT, envolve a dissociação de monóxido de carbono, formando partículas de carbono e $\mathrm{CO}_{2}$. Em uma atmosfera de CO puro sob pressão 1 a 10 atm, bombeia-se um aerossol de catalizador à base de cobalto e molibdênio através de uma rede de quartzo pulverizado armada em um forno vertical mantido entre $700^{\circ} \mathrm{C}$ e $950^{\circ} \mathrm{C}$. No topo do forno há um filtro para captura dos nanotubos formados e um sistema para reformar o $\mathrm{CO}_{2}$ em $\mathrm{CO}$ e reabastecer o ciclo.

Este método gera nanotubos com diâmetro entre $7 \AA$ e $11 \AA$ e grande concentração $(\sim 50 \%)$ das espécies $(6,5)$ e $(7,5)$, tornando-se interessante como ponto de partida para produção de amostras altamente purificadas dessas espécies.

O ambiente gasoso em que se formam esses nanotubos apresenta um empecilho para um controle mais fino da geometria ou das propriedades eletrônicas durante a síntese, dando importância aos processos de seleção pós-síntese. Outra característica desses métodos de síntese é produzir nanotubos com as extremidades fechadas, usualmente com hemisférios de fulerenos. 


\subsubsection{Técnicas de separação e isolamento}

As técnicas conhecidas para separar nanotubos em função de suas propriedades geométricas envolvem $\frac{17}{17}$ i) funcionalização química seletiva dos nanotubos - ligando covalentemente radicais químicos aos nanotubos; ii) destruição seletiva - passando correntes elétricas intensas que destróem nanotubos metálicos; iii) eletroforese; iv) cromatografia e v) ultracentrifugação, os três últimos adaptados de técnicas comuns no tratamento de biomoléculas.

A ultracentrifugação proposta por Arnold et al ${ }^{18}$ merece destaque por ser um procedimento não destrutivo e facilmente escalável para produzir nanotubos altamente selecionados à razão de gramas por dia ${ }^{19}$. Para isso, solubiliza-se os feixes de nanotubos em água com a ajuda de um surfactante. Uma vez que os feixes de nanotubos interagem muito fortemente entre si, avessos à interação com a água por sua natureza hidrofóbica, submete-se as amostras a ciclos de sonicação, em que uma sonda produz ultrassom, tipicamente na faixa dos $20 \mathrm{kHz}$, e agita a solução de surfactante e CNTs ao longo de algumas horas, quebrando os feixes e separando tubos individuais, que são em seguida encapsulados pelos surfactantes, processo conhecido como debundling. Nesse processo, as pontas dos tubos se quebram, deixando-os com as extremidades abertas ${ }^{38}$.

O próximo passo é preparar um gradiente de densidade em um tubo de centrífuga utilizando processos já conhecidos e aplicados em biologia molecular. Adiciona-se então a solução de nanotubos e surfactantes a esse gradiente e submete-se o sistema a centrifugação a cerca de $200000 \mathrm{~g}$ durante algumas dezenas de horas. Ao final do processo, os tubos se distribuem na coluna de forma que tubos mais densos se encontram na parte inferior do tubo da centrífuga e aqueles de menor densidade se posicionam próximo ao topo, conforme a Fig. 1.1. Dados de absorção no infravermelho mostram que os CNTs se distribuem no gradiente de densidade em ordem crescente de diâmetro.

\subsubsection{O papel dos surfactantes}

Um detalhe importante do processo de separação relatado é a mistura de surfactantes usada e a forma com que eles são adicionados ao sistema. Arnold ${ }^{\frac{18}{18}}$ não obteve sucesso utilizando somente dodecil sulfato de sódio (SDS, vide Fig. 4.1). Isso ocorre devido à flexibilidade da molécula de SDS e por ela não ser capaz de cobrir completamente a superfície do nanotubo 39 .

De acordo com esse processo, o surfactante utilizado durante a etapa de sonicação é o colato de sódio, sendo os demais surfactantes adicionados ao tubo da centrífuga juntamente com o gradiente de densidade e a amostra de nanotubos, participando apenas do processo de separação por densidade, não do processo de separação de feixes. 



\section{Capítulo 3}

\section{Métodos}

Testamos o modelo de admissão de surfactante no interior do tubo através de simulação computacional. Fizemos uso de técnicas que consistem em considerar os átomos como pontos materiais dotados de massa e carga sujeitos a um campo de forças oriundo da interação com seus vizinhos. Aplicamos os campos de força de duas formas neste trabalho: otimização de geometria, em que as posições dos átomos são ajustadas de modo a minimizar a energia total do sistema - levando as foças internas a valores próximos de zero e dinâmica molecular, que consiste em integrar numericamente as equações clássicas de movimento para o sistema. A otimização de geometria, também chamada de mecânica molecular, não inclui efeitos devido à temperatura, portanto é comum dizer que a mecânica molecular trata do sistema em $T=0$. Discutimos a origem, os algoritmos e as limitações da mecânica molecular no apêndice A. Detalhes das técnicas de dinâmica molecular e a forma com que se leva em conta uma temperatura finita são apresentados no apêndice B.

Neste capítulo descrevemos os parâmetros e os métodos de simulação utilizados ao longo deste trabalho.

\subsection{Parâmetros de mecânica molecular}

Cálculos de mecânica molecular e dinâmica molecular dependem de diversos parâmetros, como o campo de força, as cargas atômicas, a temperatura etc. Como realizamos diversas simulações com o objetivo de comparar seus resultados, mantivemos alguns parâmetros de simulação fixos.

Realizamos todos os cálculos através do módulo OFF (Open ForceField) do pacote Cerius ${ }^{240}$ com o campo de força CVFF ${ }^{41}$ (Consistent-Valence Force Field, campo de força de valência consistente), parametrizado para substâncias orgânicas, compatíveis com as deste trabalho. Comparamos o 
desempenho desse campo de força em reproduzir conformações de dímeros de naftaleno ${ }^{42 \mid 43}$ com o resultado de outros campos de força, pois nossas simulações envolvem a interação não ligada de compostos cíclicos de carbono. O CVFF apresentou melhores resultados para esse sistema e é capaz de reproduzir o comportamento de ligações de hidrogênio - importantes quando se simula moléculas de água - dada uma adequada distribuição de cargas ${ }^{44}$. O campo de forças CVFF adota para as moléculas de água parâmetros provenientes do modelo SPC $\underline{45}$ (Simple Point Charge, carga pontual simples), portanto em nossas simulações a carga nos átomos na molécula de água foi mantida, em unidades da magnitude da carga do elétron, em 0.41 em cada hidrogênio e -0.82 no oxigênio.

Calculamos as demais cargas atômicas através do método de equilíbrio de cargas de Rappé-Goddard ${ }^{[46}$ com a molécula de surfactante isolada em sua geometria de equilíbrio. Uma vez estabelecidas as cargas atômicas, mantivemonas fixas durante as simulações.

Calculamos as geometrias dos nanotubos através do campo de força CVFF a partir das coordenadas geradas pelo programa disponível no livro de Gene e Mildred Dresselhaus ${ }^{16}$ com carga líquida nula em cada átomo.

Como a dinâmica molecular é uma técnica de integração numérica, o passo de integração é um parâmetro fundamental para garantir a estabilidade e a rapidez da simulação. Em todos os casos, utilizamos passos de integração de 1 fs. Buscando reproduzir resultados experimentais e configurações otimizadas, portanto de baixa energia, devemos permitir que a energia total do sistema varie ao longo da simulação. Para isso, adotamos algoritmos NVT, em que o Número de partículas, o $V$ olume da caixa de simulação e a Temperatura são mantidos constantes e $N P T$, nos quais o Número de partículas, a Pressão e a Temperatura são mantidos constantes.

Uma vez que a dinâmica molecular só tem acesso a variáveis como a posição, a velocidade e a força sobre os átomos, a temperatura é controlada indiretamente, através de algoritmos conhecidos como termostatos. Em todas as simulações adotamos o termostato de Nosé-Hoover ${ }^{47}$, que coloca a temperatura como uma variável dinâmica na hamiltoniana do sistema, levando a simulação a reproduzir uma distribuição no ensemble canônico. Descrevemos em detalhe o termostato de Nosé-Hoover no apêndice B.1 Em todos os casos, a temperatura foi fixada em $300 \mathrm{~K}$.

\subsection{Protocolo de solvatação}

Como este trabalho envolve a interação nanotubo-surfactante em água, preparamos uma caixa de simulação com água para servir de base para o 
protocolo de solvatação. Para isto, partimos de um modelo de gelo hexagonal preenchendo uma caixa de simulação de $35 \times 35 \times 90 \AA$. O número de moléculas de água e o volume da caixa foram ajustados para se obter uma densidade de $1 \mathrm{~g} / \mathrm{cm}^{3}$. Deixamos essa caixa relaxar em dinâmica molecular $N V T$ a $300 \mathrm{~K}$ até que a distribuição radial entre átomos de oxigênio $g_{O-O}$ reproduzisse a da literatura ${ }^{48}$.

O protocolo de solvatação consiste então em copiar uma região dessa caixa com dimensões comparáveis à da caixa de simulação em que se pretende trabalhar. Essa nova caixa é então deixada relaxar em dinâmica molecular com os mesmos parâmetros e, uma vez atingido o equilíbrio, o soluto é inserido no modelo.

A simples inserção do soluto na caixa de simulação, entretanto, apresentou a possibilidade de átomos muito próximos ou mesmo intersecção entre moléculas de água e de soluto, o que levaria a forças muito intensas e velocidades atômicas inverossímeis. Para contornar esse problema, excluímos as moléculas de água com um átomo de oxigênio cuja distância a outro átomo qualquer fosse menor que três quartos da soma dos raios de van der Waals dos átomos envolvidos. Em seguida, mantendo fixas as posições dos átomos do soluto e considerando as moléculas de água como corpos rígidos, procedemos a minimização de energia do sistema, utilizando um critério grosso de convergência, que pára a otimização quando a força quadrática média nos átomos se torna menor que $10^{-1} \mathrm{kcal} / \mathrm{mol}$. $\AA$. Desse modo, impedimos o surgimento de forças excessivas no início da dinâmica molecular sem perturbar em demasia a distribuição de moléculas de solvente. 



\section{Capítulo 4}

\section{Interação entre nanotubos e surfactantes}

Para testar modelo em que moléculas de surfactante são atraídas para o interior do nanotubo, precisamos inicialmente saber se é possível que elas permaneçam nessa posição. Testamos isso calculando a energia potencial do sistema nanotubo-surfactante em diversas configurações e comparamos os valores obtidos com o surfactante no interior do tubo e em seu exterior.

Realizamos esses cálculos em duas condições: em vácuo, ou seja, na ausência de outras moléculas além do surfactante e do nanotubo; e em solução, caso em que as moléculas de interesse encontram-se dissolvidas em água de modo a reproduzir as condições experimentais.
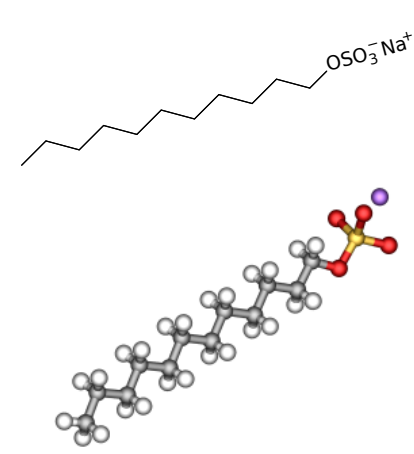

(a) Dodecil sulfato de sódio (SDS)
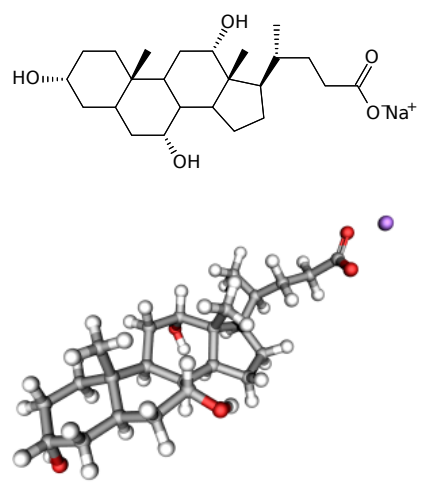

(b) Colato de sódio (SC)<smiles>COCCOc1cc2ccccc2cc1OCCOC</smiles>

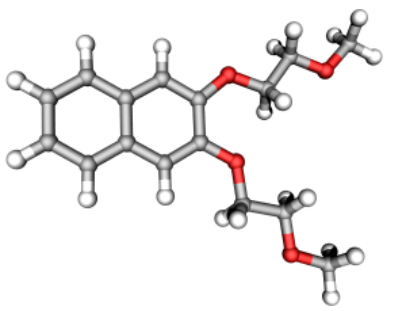

(c) 2,3-bis[2-metoxietoxil]naftaleno (MEN)

Figura 4.1: Estruturas dos três surfactantes tratados neste trabalho.

Consideramos três moléculas anfifílicas como surfactantes: Um surfactante comumente utilizado em laboratório, dodecil sulfato de sódio (SDS); 
um sal de bile, colato de sódio (SC), ambos empregados no processo de separação por gradiente de densidade ${ }^{18}$ e um surfactante aromático não iônico, 2,3-bis[2-metoxietoxil]-naftaleno (MEN), proposto por nós como um candidato para expandir o método para nanotubos de outros diâmetros devido a seu segmento apolar aromático - que deve aumentar a aderência com a superfície do tubo - e por ser não iônico ${ }^{49}$. Estruturas dessas moléculas estão representadas na Figura 4.1.

\subsection{Modelagem dos nanotubos e surfactantes}

As simulações envolvendo um nanotubo e uma molécula de surfactante consistiram na otimização de geometria dos sistemas buscando a configuração de menor energia. Iniciamos otimizando os vinte e seis tubos originalmente selecionados pelo processo de ultracentrifugação $\frac{18}{18}$, apresentados a seguir, com seus diâmetros, na tabela 4.1. Esses tubos foram modelados com comprimento pelo menos três vezes maior que o comprimento típico das moléculas de surfactante para eliminar possíveis efeitos de borda. Experimentalmente, o processo de sonicação quebra os nanotubos $\frac{38}{38}$, portanto modelamos essas moléculas com as bocas abertas e sem saturar as ligações nas pontas. Na realidade, não temos informação sobre qual é a geometria da borda dos nanotubos quebrados e, por simplicidade, modelamos as bordas da maneira mais regular possível. A falta de saturação da valência do carbono nas ligações de borda não tem conseqüências perniciosas pois em mecânica molecular — um tratamento clássico - a valência dos átomos é uma propriedade atribuída em vez de calculada.

Tabela 4.1: Nanotubos selecionados pelo processo de centrifugação de Arnold et al ${ }^{[18}$ e empregados neste trabalho.

\begin{tabular}{|c|c||c|c||c|c|}
\hline Tubo & Diâmetro $(\AA)$ \\
\hline$(5,5)$ & 6,78 & Tubo & Diâmetro $(\AA)$ & Tubo & Diâmetro $(\AA)$ \\
\hline$(6,5)$ & 7,47 & $(7,6)$ & 8,82 & $(11,4)$ & 10,53 \\
$(9,1)$ & 7,47 & $(19,4)$ & 9,03 & $(13,1)$ & 10,59 \\
$(8,3)$ & 7,71 & 9,39 & $(8,8)$ & 10,85 \\
$(9,2)$ & 7,95 & $(7,7)$ & 9,49 & $(10,6)$ & 10,96 \\
$(6,6)$ & 8,14 & $(9,6)$ & 9,52 & $(14,0)$ & 10,96 \\
$(7,5)$ & 8,17 & 9,62 & $(15,0)$ & 11,74 \\
$(8,4)$ & 8,29 & $(8,7)$ & 10,18 & $(9,9)$ & 12,20 \\
$(10,2)$ & 8,72 & $(13,0)$ & 10,18 & $(10,8)$ & 12,23 \\
\hline
\end{tabular}

Otimizamos pelo mesmo processo a geometria os surfactantes, em sua con- 
figuração não ionizada e com as cargas calculadas como descrito na Seção 3.1

\subsection{Energia de interação no vácuo}

O próximo passo foi montar sistemas com uma molécula de surfactante e um nanotubo, cada par em duas configurações: surfactante no interior do tubo e sobre sua superfície, como na Fig. 4.2 e então realizar mais um processo de otimização de geometria.

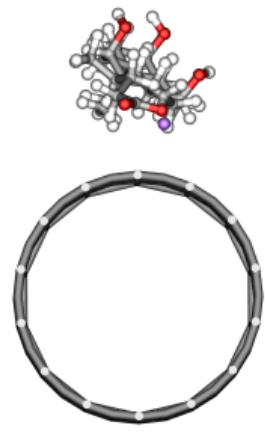

(a) $\mathrm{SC}$ sobre tubo $(14,0)$

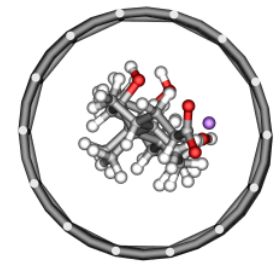

(b) $\mathrm{SC}$ em tubo $(14,0)$

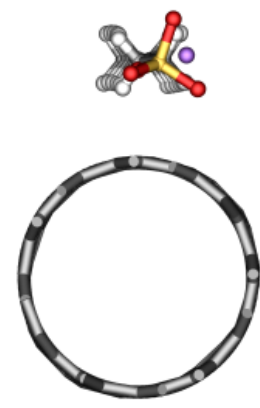

(c) SDS sobre tubo $(7,5)$

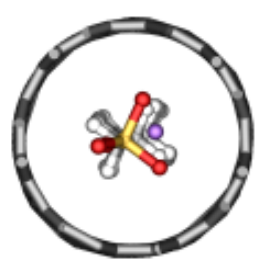

(d) SDS em tubo $(7,5)$

Figura 4.2: Configurações de nanotubos e surfactantes (fora de escala)

Definimos, então, a energia de interação $E_{\text {inter }}$ como a diferença entre energia do sistema composto $E_{\mathrm{NT}+\text { surf }}$ e a soma de suas partes:

$$
E_{\text {inter }}=E_{\mathrm{NT}+\text { surf }}-\left(E_{\mathrm{NT}}+E_{\text {surf }}\right)
$$

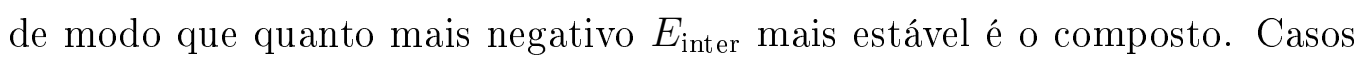
em que $E_{\text {inter }}$ é positivo podem ser considerados instáveis e improváveis de se formar espontaneamente.

Cabe ressaltar aqui que estamos interessados nos efeitos da geometria e da deformação do tubo, portanto todos os átomos do sistema, tanto do surfactante quanto do nanotubo, foram mantidos livres para se mover sob ação das forças internas. Este pode ser considerado um diferencial deste trabalho, uma vez que normalmente os átomos do nanotubos são mantidos fixos ${ }^{50} \mathrm{ou}$ considerados paredes contínuas que interagem com o conteúdo do tubo através de um potencial do tipo van der Waals ${ }^{51}$. Essa liberdade de deslocamento faz com que mudanças na energia interna do nanotubo devido a deformações causadas pela presença do surfactante - analogamente, mudanças na energia interna do surfactante devido à presença do nanotubo — sejam refletidas 
no valor de $E_{\text {inter }}$, efetivamente levando em conta os efeitos da deformação na energia de ligação e na análise sobre a viabilidade das configurações obtidas.

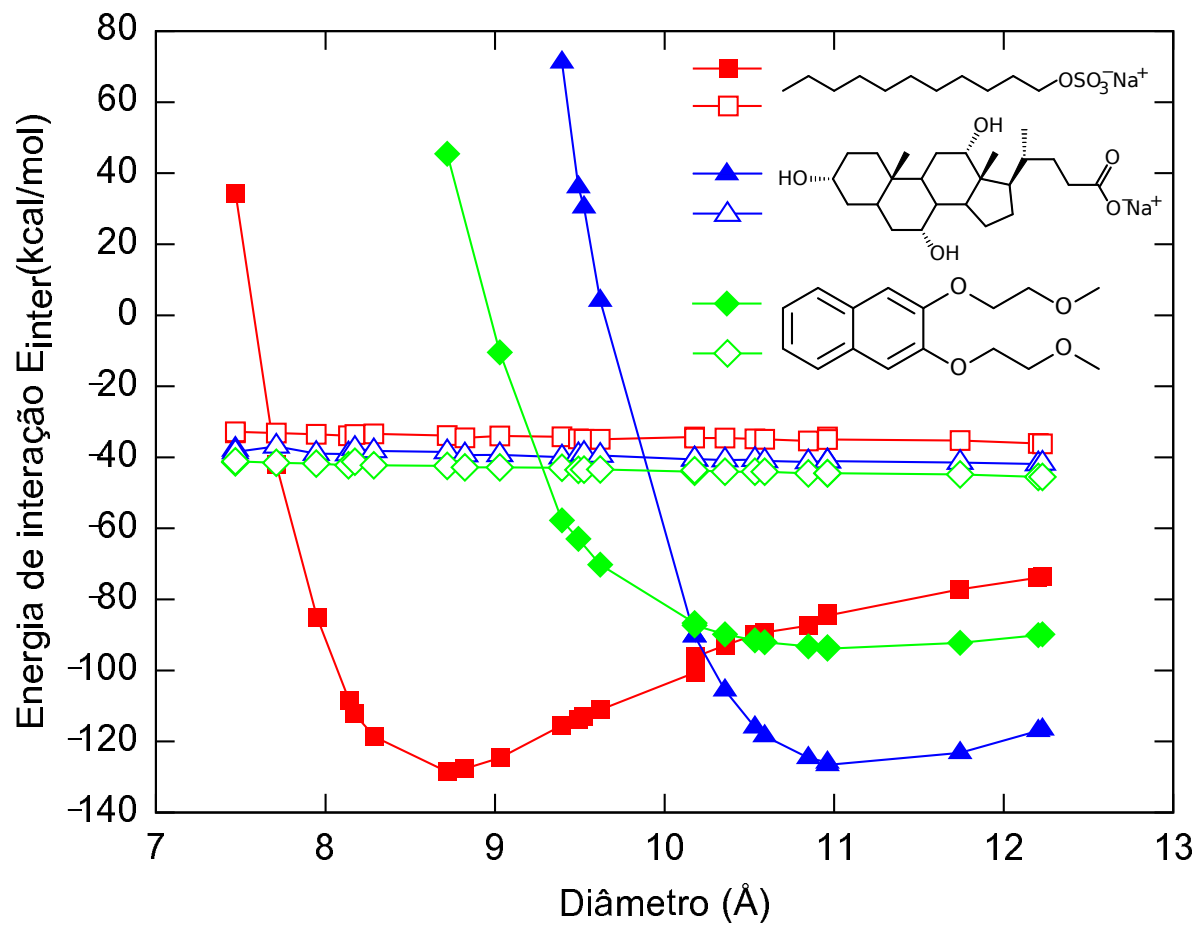

Figura 4.3: Energia de interação do sistema nanotubo-surfactante. Energias em $\mathrm{kcal} / \mathrm{mol}$ em função do diâmetro do nanotubo $(\AA)$. Símbolos vazios: surfactante sobre a superfície do tubo. Símbolos preenchidos: surfactante no interior do nanotubo. As estruturas moleculares dos surfactantes estão representadas ao lado de seus símbolos: quadrados $(\square)$ vermelhos, SDS; triângulos $(\triangle)$ azuis, SC; diamantes $(\diamond)$ verdes, MEN.

Observando o resultados desses cálculos na Fig. 4.3, notamos uma dependência muito fraca da energia de ligação com o diâmetro do nanotubo quando o surfactante está sobre a superfície do tubo mas, como previsto, essa relação é aproximadamente decrescente, com uma interação ligeiramente mais intensa à medida que o diâmetro do nanotubo aumenta e sua superfície se aproxima de uma estrutura planar. Percebemos também uma preferência da superfície dos nanotubos por surfactantes mais planares, de modo que o MEN interage mais fortemente com a superfície do tubo que o SC e este mais fortemente que o SDS.

Quanto às moléculas no interior do nanotubo, observamos primeiramente um diâmetro crítico abaixo do qual a molécula não é admitida no interior da cavidade. É um resultado intuitivo quando levamos em conta a possibilidade da molécula de surfactante não "caber" em tubos de diâmetro muito 
pequeno. Para o SDS, a molécula com o menor raio de giração, esse diâmetro é de cerca de 7,6 , para o SC, $9,7 \AA$ e no caso do MEN, $9 \AA$, considerando como diâmetro crítico aproximadamente aquele em que a curva de energia de ligação muda de sinal na Fig. 4.3. No caso de diâmetros superiores a esse diâmetro crítico, notamos que a energia de interação segue decrescendo, atinge um mínimo e eventualmente volta a aumentar, denunciando a existência de um diâmetro ótimo em que a presença do surfactante no interior do tubo é mais favorecida. Também podemos notar que, para diâmetros superiores ao diâmetro ótimo, a interação do nanotubo com o surfactante em seu interior é de duas a três vezes mais intensa que com a molécula sobre sua superfície.

É notável o fato de que cada surfactante apresenta interação mais intensa no interior de nanotubos diferentes, em particular, o diâmetro ótimo para um nanotubo conter uma molécula de SDS é de $8,72 \AA$ e no caso do SC e do MEN esse diâmetro é de 10,96 A. Notamos também que o diâmetro ótimo de admissão do SDS é menor que o diâmetro mínimo que pode admitir uma molécula de $\mathrm{SC}$ em seu interior.

Apesar de o MEN apresentar um diâmetro crítico menor que o do SC, observamos que a vantagem energética em ter a molécula dentro do tubo em relação à superfície é cerca da metade desse ganho com SC. Isso se deve ao fato de ela interagir mais fortemente com o exterior do nanotubo através de seus anéis aromáticos e suas caudas polares serem bastante flexíveis, mas não poderem ser colocadas muito próximas uma da outra devido aos átomos de oxigênio tenderem a se repelir. Essa flexibilidade também "achata" a curva de energia em função do diâmetro do tubo, já que tubos maiores permitem que as caudas polares se afastem mais, buscando conformações mais estáveis.

É importante notar que esses resultados de mecânica molecular representam o sistema à temperatura zero, portanto não levam em conta a agitação das moléculas. A ordem de grandeza das energias envolvidas, entretanto, nos mostra que a diferença entre o surfactante no interior do tubo e em sua superfície é significativa, uma vez que essa diferença atinge os $100 \mathrm{kcal} / \mathrm{mol}$. Em comparação, à temperatura ambiente, $k T=0,6 \mathrm{kcal} / \mathrm{mol}$, ou seja, barreiras de energia inferiores a $0,6 \mathrm{kcal} / \mathrm{mol}$ são facilmente transpostas à temperatura ambiente.

Outra coisa interessante a se observar é que a quiralidade do nanotubo não desempenha um papel importante na afinidade dos surfactantes, tanto sobre a superfície quanto no interior da cavidade, já que tubos com ângulos quirais bem distantes mas diâmetros próximos, como $(12,0)$ e $(7,7)$, têm energias de interação próximas entre si.

Vemos então que, se for possível que moléculas de surfactante se desloquem para o interior do nanotubo, essa configuração será a energeticamente mais favorável no caso de nanotubos de diâmetro adequado. Além disso, 
as relações energéticas nos mostram que, dado um conjunto de nanotubos de diversos diâmetros entre 7 e $13 \AA$, aqueles de diâmetro maior terão uma população maior de SC que de SDS em seu interior, enquanto aqueles de diâmetro menor não admitirão moléculas de SC, somente de SDS.

Assim, mostramos que não apenas um dos surfactantes, mas a presença de ambos é importante para o sucesso da separação de nanotubos em função de seu diâmetro através de um gradiente de densidade.

\subsection{Interação em meio aquoso}

Para levarmos em conta o efeito da água nessa relação nanotubo-surfactante não é praticável utilizar apenas minimização de energia como no caso anterior, já que o grande número de graus de liberdade adicionados pelas moléculas de água dá origem a muitos mínimos locais, que não necessariamente representam a configuração mais provável para o sistema à temperatura ambiente. Por isso preparamos uma caixa de simulação de $35 \times 35 \times 90 \AA$ e solvatamos em água um nanotubo $(14,0)$ de acordo com o protocolo da Seção 3.2, tomando o cuidado de manter o interior do tubo livre de moléculas de água. Em cópias dessa caixa incluímos os surfactantes nas diversas configurações de estudo, novamente cuidando para evitar sobreposição de moléculas. Com isso, a caixa de simulação continha um total de 3190 moléculas de água. Além das duas configurações de surfactante estudadas na Seção 4.2. testamos também a molécula próxima à boca do tubo, com a cabeça polar voltada para o nanotubo e afastada dele, como ilustrado na Fig. 4.4.

Temos, então, quatro caixas de simulação com um tubo $(14,0)$ em água para cada um dos dois surfactantes: SC e SDS. Realizamos simulações de dinâmica molecular $N V T$ durante 10 ps para levar cada um desses sistemas a uma condição de equilíbrio e então deixamos o sistema evoluir durante 5 ps. Tomamos dados a cada 10 fs para calcular a energia potencial média do sistema e seu desvio padrão. Estas simulações foram particularmente longas - cerca de duas semanas para a obtenção da Fig. 4.4 - devido à grande quantidade de átomos envolvida e ao fato de mantermos livres todos os graus de liberdade.

Esses valores, dispostos na Fig. 4.4, mostram que na presença de água o SDS interage mais fortemente com a superfície do nanotubo $(14,0)$ que com seu interior. Essa relação é oposta ao que se observou em vácuo (fig. 4.3). O mesmo não ocorre com o SC, cujo posicionamento no interior da cavidade é mais favorecido do que se estivesse aderido à superfície externa. Lembramos que o $(14,0)$ é o tubo que interage, em vácuo, mais fortemente com o $\mathrm{SC}$ em 


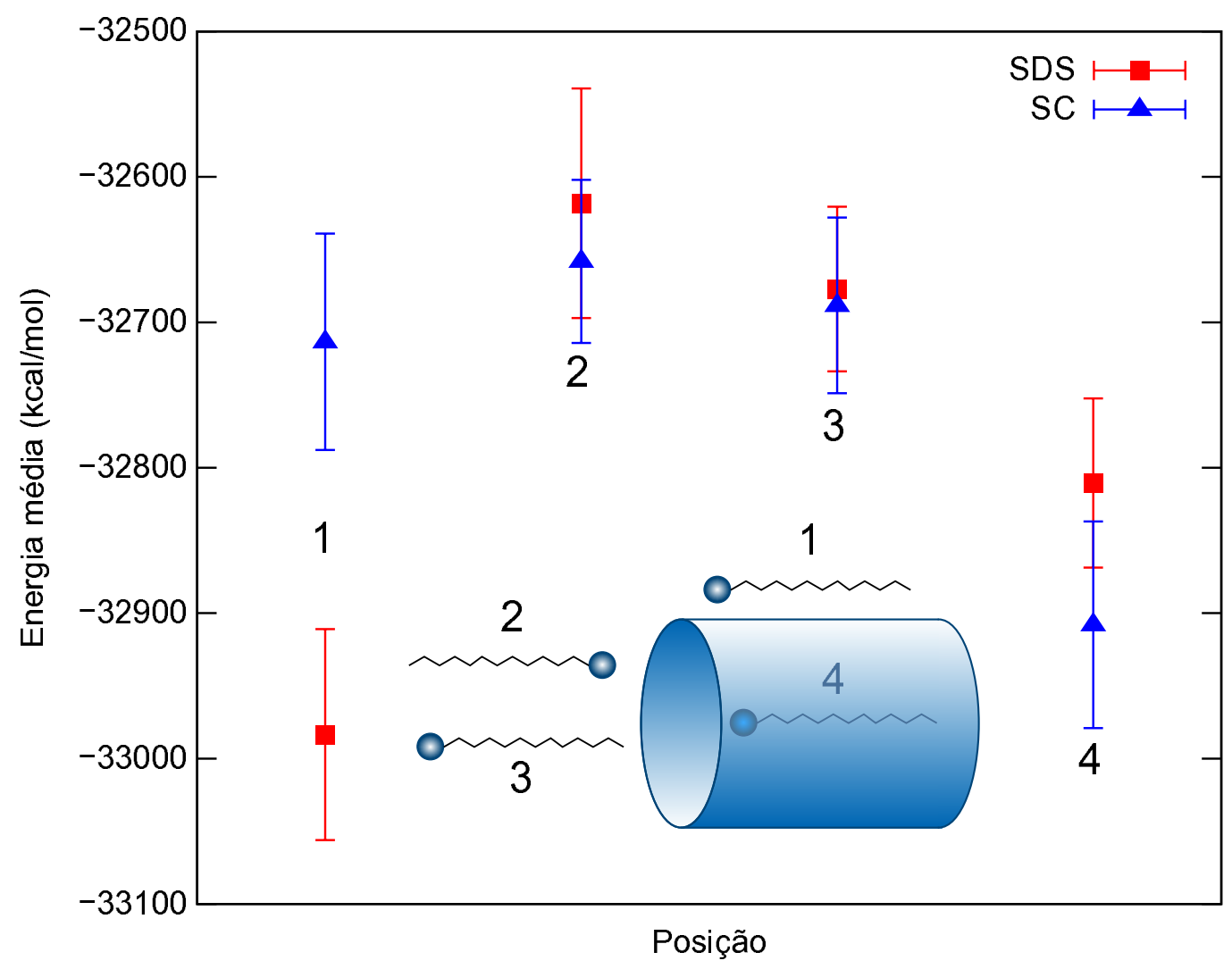

Figura 4.4: Efeito da água na interação entre nanotubo e surfactante Energia potencial em $\mathrm{kcal} / \mathrm{mol}$ em função da posição do surfactante perante o nanotubo $(14,0)$ : (1) Sobre a superfície do tubo; (2) próximo à boca do tubo, com a cabeça polar voltada para dentro; (3) próximo à boca do tubo, com a cabeça polar voltada para fora e (4) no interior do tubo. Barras de erro são o desvio padrão ao longo da simulação. Quadrados ( $\square$ ) vermelhos, SDS; triângulos $(\triangle)$ azuis, SC.

seu interior (Fig. 4.3).

Vamos nos voltar agora ao tubo $(7,5)$, aquele em cujo interior o SDS é mais estável. Uma vez que a Fig. 4.4 nos mostra que a energia potencial do surfactante à boca do tubo praticamente não varia quando mudamos a orientação de sua cabeça polar, simplificamos a caixa de simulação, reduzindo o espaço disponível próximo à boca do tubo. Dessa forma, a caixa de simulação para o tubo $(7,5)$ tem dimensões de $25 \times 30 \times 49 \AA$ e contém 944 moléculas de água, uma molécula de SDS e uma secção de $43 \AA$ de comprimento de um nanotubo $(7,5)$. Iniciamos as simulações $N V T$ com um período de termalização de 50 ps e tomamos dados de energia potencial ao longo de 5 ps após a termalização.

O sistema em que a molécula de SDS se encontra sobre a superfície do 
nanotubo teve energia potencial média de -13476(47) $\mathrm{kcal} / \mathrm{mol}$ e o caso em que o surfactante se encontra no interior da cavidade apresentou energia potencial média de $-13658(48) \mathrm{kcal} / \mathrm{mol}$, uma diferença de aproximadamente 3,8 desvios padrão favorecendo a configuração interna, confirmando o comportamento seletivo do SDS para nanotubos de menor diâmetro. 


\section{Capítulo 5}

\section{Dinâmica molecular}

Vimos ao longo do Capítulo 4 que cada surfactante interage com intensidades diferentes se situado sobre a superfície ou no interior de nanotubos de dado diâmetro. Também mostramos que há um diâmetro ótimo de nanotubo com que o surfactante interage mais intensamente se presente em seu interior.

O próximo passo é verificar se o interior do nanotubo é acessível ao surfactante nas condições do procedimento de separação. Para tanto, executamos simulações de dinâmica molecular a fim de verificar se uma molécula de surfactante próxima à boca de um nanotubo é atraída para o interior da cavidade ou se existe uma barreira energética que possa dificultar ou impedir esse fenômeno.

\subsection{Dinâmica molecular em vácuo}

Inicialmente, procuramos por barreiras devidas unicamente à estrutura do nanotubo, portanto realizamos simulações de dinâmica $N V T$ com uma secção de $30 \AA$ de comprimento de um nanotubo $(14,0)$ e uma molécula de $\mathrm{SC}$ colocada próximo a uma das extremidades do tubo.

Podemos observar na Fig. 5.1 que a molécula de surfactante é atraída para o interior do CNT em cerca de 5 ps, mostrando que não há uma barreira significativa dificultando a entrada da molécula na cavidade do nanotubo.

Observando a Fig. 5.2 também notamos que, uma vez que a molécula entra no nanotubo, continua sua viagem até a outra extremidade, onde encontra resistência e retorna, realizando um movimento oscilatório no interior da cavidade. Essa oscilação é amortecida enquanto a energia cinética do surfactante é transmitida para os modos vibracionais do CNT, de modo que a molécula atinge o repouso no interior da estrutura. 

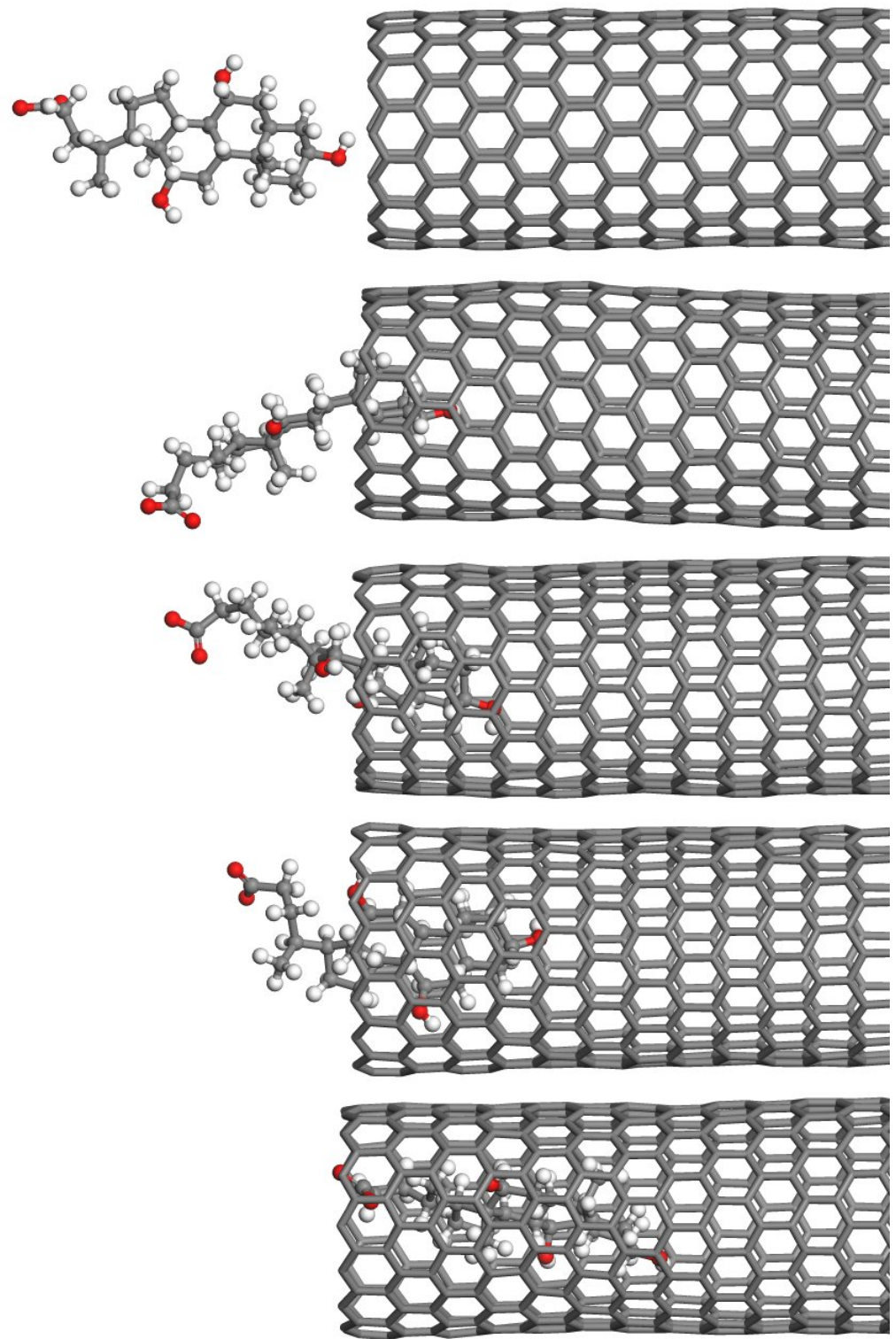

Figura 5.1: Passos de dinâmica molecular em vácuo envolvendo um nanotubo $(14,0)$ e colato de sódio. O intervalo entre cada figura é de 1 ps 


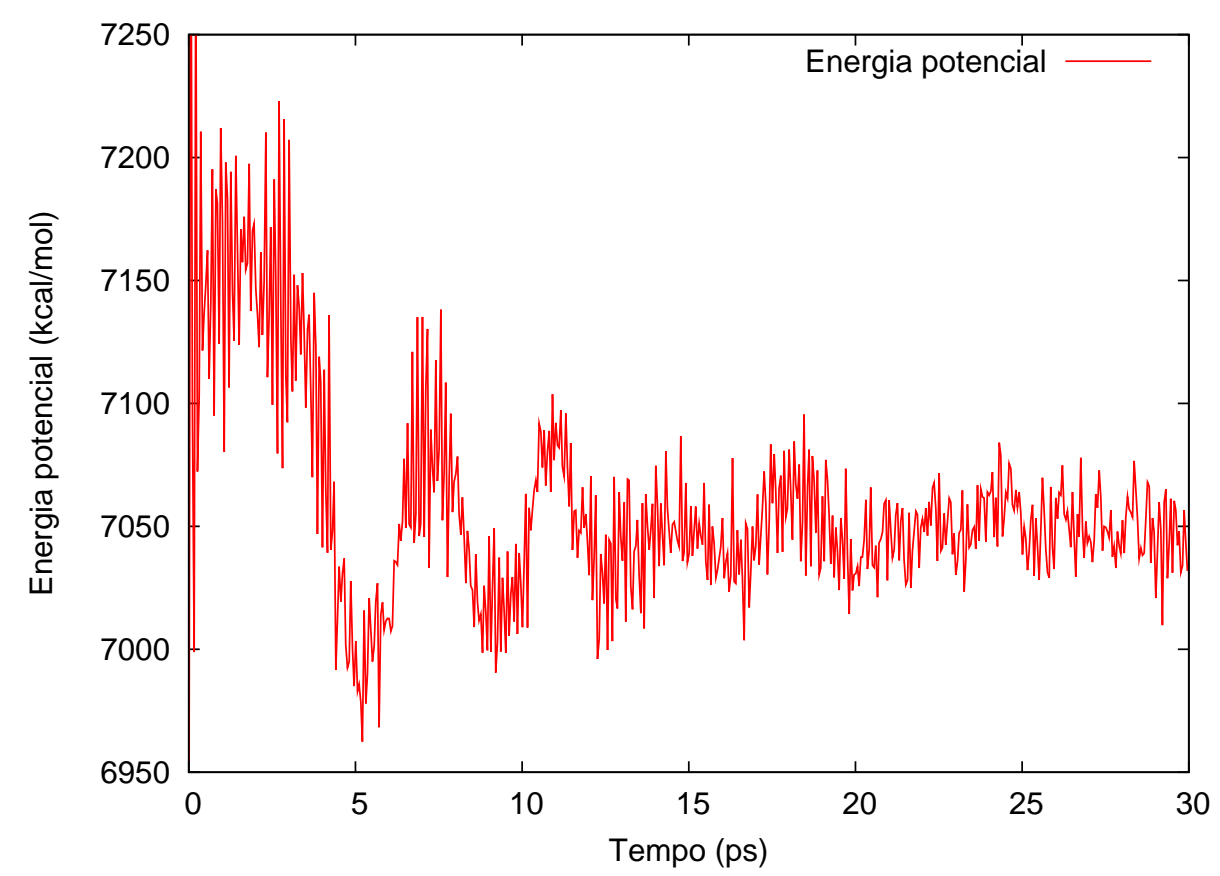

Figura 5.2: Energia potencial ao longo da simulação envolvendo um nanotubo $(14,0)$ e colato de sódio. O mínimo de energia em $t \sim 5$ ps e o máximo em $t \sim 8$ ps mostram a existência de uma barreira energética que impede $o$ surfactante de escapar do interior do tubo.

\subsection{O efeito da água}

Tendo comprovado a possibilidade de moléculas de surfactante entrarem na cavidade do nanotubo, iniciamos simulações similares que levam em conta o papel da água. Ao longo dos cálculos da Seção 4.3, nenhuma molécula de água entrou por conta própria no nanotubo, levando-nos a entender que o aumento no número de graus de liberdade induzido pela inclusão de moléculas de água faz com que o sistema leve muito mais tempo para percorrer no espaço de fase a região de interesse para analisarmos com confiabilidade a existência de uma barreira. Desse modo, simulações desses sistemas a $1 \mathrm{~g} / \mathrm{cm}^{3}$ levariam um tempo impraticável para trazer algum resultado.

Por isso, simplificamos a abordagem solvatando uma molécula de SC em uma caixa com água como descrito na Seção 3.2 O próximo passo foi fazer caixas de simulação similares àquelas utilizadas para os cálculos da Seção 5.1, contendo um nanotubo $(15,0)$ e a molécula de SC juntamente com 92 moléculas de água vizinhas. Além disso, mantivemos a extremidade oposta do nanotubo fixa de modo a emular o comportamento de um tubo longo e massivo sem cercear os modos vibracionais e deformações na estrutura, importantes para a admissão da molécula em seu interior. 

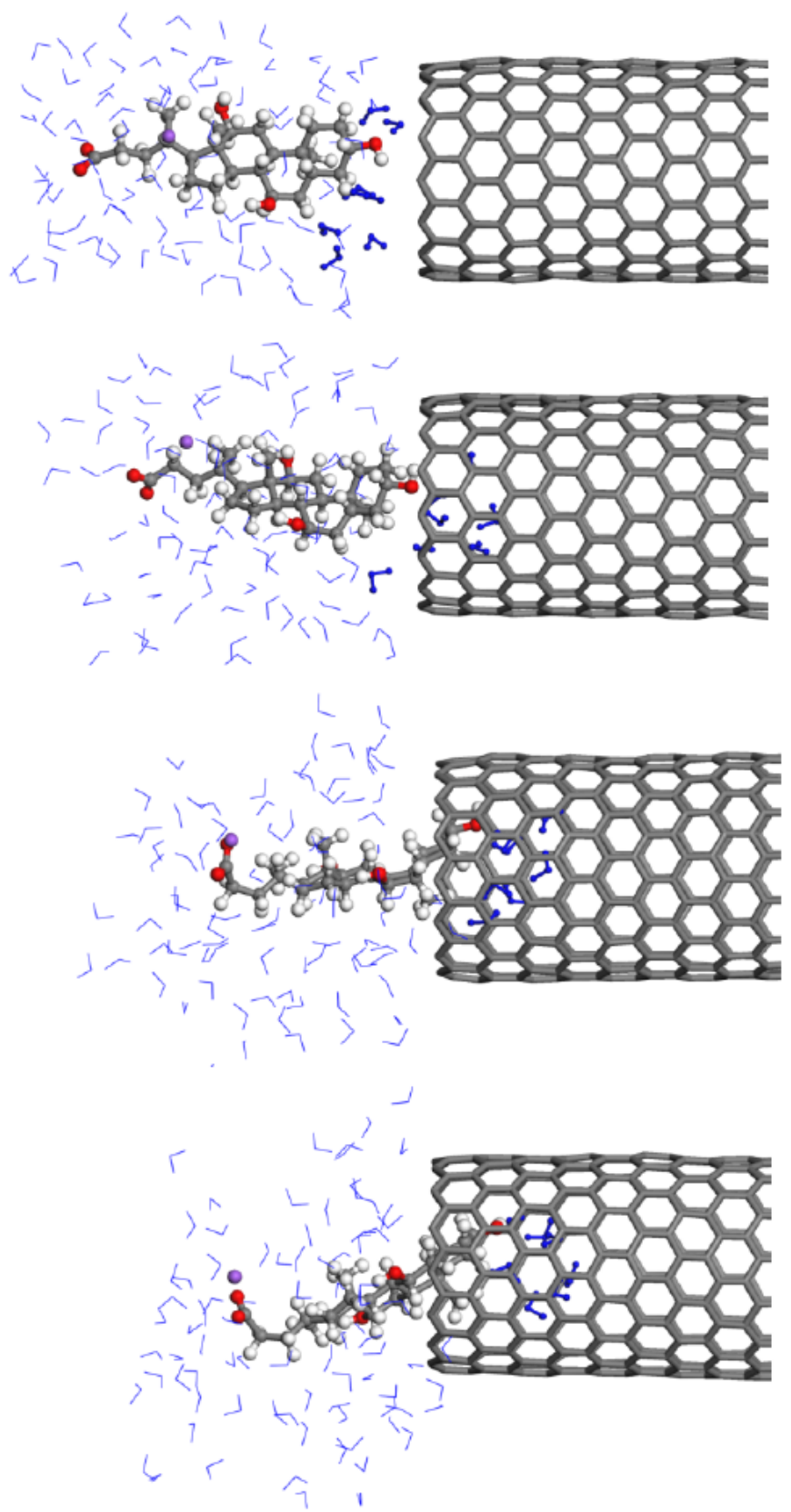

Figura 5.3: Arrasto de moléculas de água para o interior do nanotubo. Passos da dinâmica molecular envolvendo um nanotubo $(15,0)$ e colato de sódio envolvido por 92 moléculas de água (em azul). As moléculas destacadas foram empurradas pelo surfactante para o interior da cavidade. O intervalo entre cada figura é de 10 ps 
A Fig. 5.3 mostra o resultado dessa simulação e nela observamos que de fato a velocidade dos eventos é consideravelmente reduzida devido à inclusão dos novos graus de liberdade oriundos das moléculas de água. Além disso, notamos que ainda existe uma força de atração para o interior da cavidade do nanotubo, mesmo com a presença de moléculas de água. A interação entre o surfactante e a água, entretanto, é suficiente para manter moléculas do solvente aderidas ao SC, especialmente pelas pontes de hidrogênio nas hidroxilas. Essas moléculas de água acabam "arrastadas" para o interior do nanotubo pelo surfactante.

Para verificar se o surfactante é realmente responsável pela atração de água para o interior da cavidade do nanotubo, repetimos a simulação nas mesmas condições substituindo o aglomerado de água e colato de sódio por um aglomerado de 154 moléculas de água. O resultado é apresentado na Fig. 5.4, onde vemos que as moléculas de água não se deslocam para o interior do nanotubo, mantendo-se coesas em seu aglomerado. Esse resultado nos mostra que, de fato, o surfactante desempenha um papel fundamental na separação de nanotubos em função do diâmetro através de gradiente de densidade, uma vez que permite a entrada de água numa cavidade hidrofóbica.

Os surfactantes devem também ser capazes de formar estruturas mais densas e compactas que estruturas ordenadas já previstas na literatura envolvendo somente moléculas de água, pois apresentam afinidade tanto com a água quanto com a superfície interna do nanotubo e podem formar uma "ponte" entre as duas estruturas. 

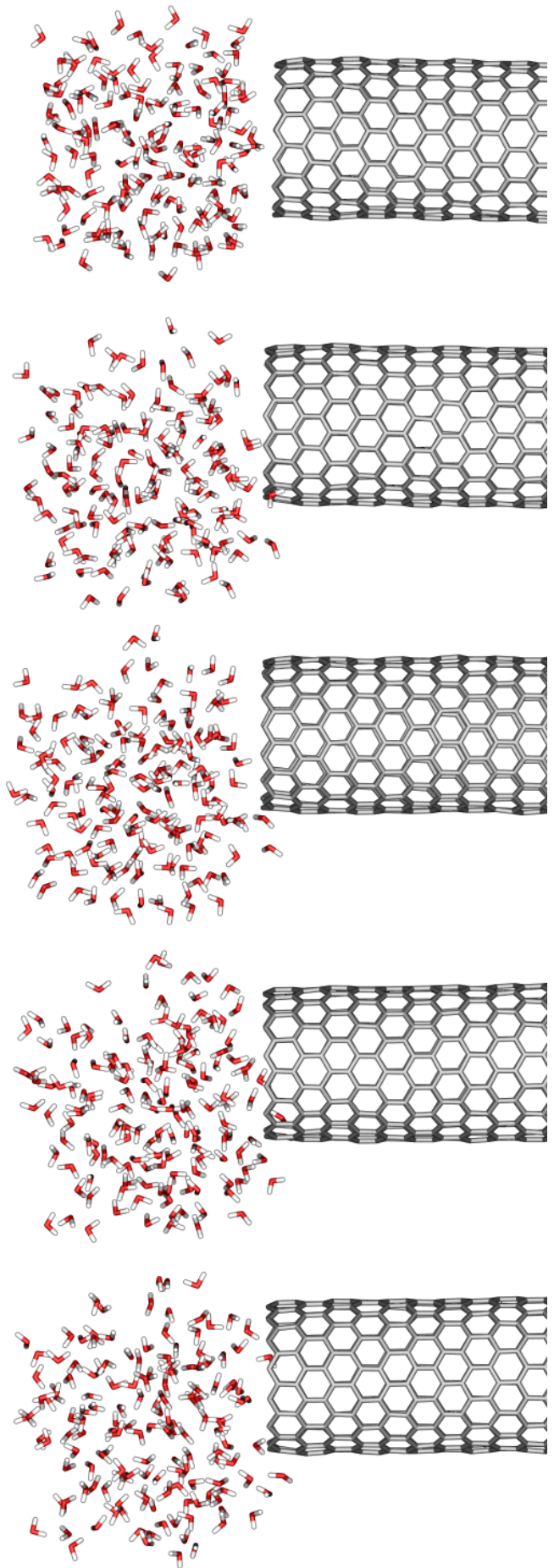

Figura 5.4: Dinâmica molecular: Água na entrada do nanotubo. Passos da dinâmica molecular envolvendo um nanotubo $(15,0)$ e 154 moléculas de água (em vermelho e branco). A ausência de surfactante impede que moléculas de água sejam atraídas para a cavidade do nanotubo. O intervalo entre cada figura é de $10 \mathrm{ps}$ 


\section{Capítulo 6}

\section{Densidade}

Agora que vimos que os nanotubos atraem moléculas de surfactante para seu interior e que elas podem arrastar consigo moléculas de água, vamos calcular o efeito do preenchimento dos CNTs em sua densidade. Devemos levar em conta também a camada de surfactante aderida à superfície dos tubos, responsável por separá-los dos feixes. Isso é um desafio devido à dificuldade em se definir o volume do sistema. Aproximar o nanotubo por um cilindro com diâmetro dado por (2.1) ${ }^{16}$, por exemplo, é sujeito a certa imprecisão por conta de uma região de exclusão em torno do CNT, de espessura comparável ao raio de van der Waals do carbono, que não pode ser ocupada por átomos do solvente ou do surfactante. A possibilidade de o nanotubo se deformar devido ao seu conteúdo também pesa contra a aproximação cilíndrica.

Por isso, desenvolvemos um modelo em que o nanotubo é recoberto por uma camada de surfactante de densidade média $\rho_{\text {surf }}$ e espessura constante $t$, como mostra a Figura 6.1. Calculamos, então a densidade média do nano-

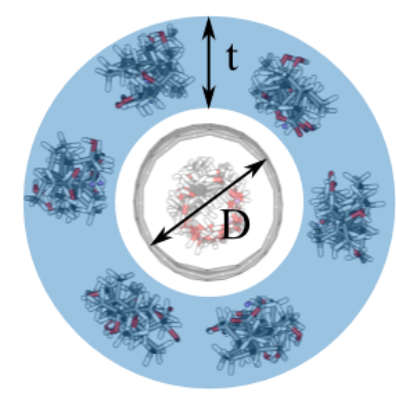

Figura 6.1: Esquema de cálculo da densidade de nanotubos em solução

tubo $\rho_{\text {solid }}$ através de um modelo em estado sólido, em que tubos infinitos (em condições periódicas de contorno) se arranjam em feixes hexagonais. Finalmente, combinamos as densidades dos nanotubos calculada em estado sólido 
com a camada de surfactante, obtendo valores que podem ser comparados com resultados experimentais.

Na Seção 6.1 detalhamos o processo de cálculo de $\rho_{\text {solid }}$ e apresentamos seus resultados. Em seguida, apresentamos na Seção 6.2 a forma com que levamos em conta a camada de surfactante e seu efeito na densidade dos tubos em solução.

\subsection{Densidade no estado sólido}

Inicialmente, simulamos o número ideal de moléculas de água no interior de seis nanotubos, $(6,6),(7,7),(8,3),(10,2),(13,0)$ e $(15,0)$, na presença e na ausência do surfactante em seu interior. Para tanto, um trecho de nanotubo de comprimento comparável a uma vez e meia o comprimento da molécula de surfactante foi posto em uma caixa de simulação de dimensões $20 \AA$ maiores que as dimensões (comprimento e diâmetro) do tubo, preenchida com água a $1 \mathrm{~g} / \mathrm{cm}^{3}$ previamente termalizada de acordo com o procedimento da Seção 3.2 .

Num processo semelhante, solvatamos uma molécula de cada surfactante, deixando cada sistema relaxar por mais 50 ps. Temos ao todo três caixas para solvatação: um apenas com água e uma com cada surfactante. Solvatamos então cada um dos 6 nanotubos em cada uma dessas três caixas, com o cuidado de alinhar o eixo do tubo com o eixo do surfactante. Submetemos as

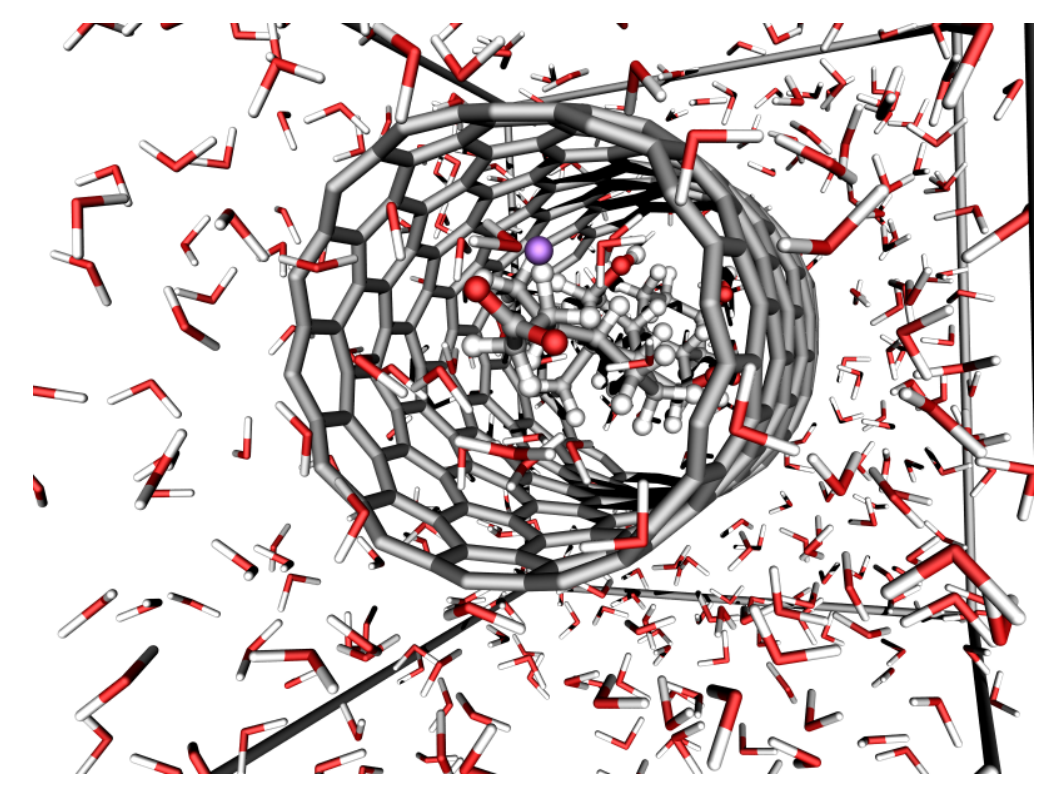

Figura 6.2: Caixa de simulação para obtenção do número ótimo de moléculas de água no interior do tubo 
caixas de simulação assim preparadas (vide Fig. 6.2) a dinâmica molecular NPT à temperatura de $300 \mathrm{~K}$ durante $500 \mathrm{ps,} \mathrm{permitindo} \mathrm{que} \mathrm{moléculas} \mathrm{de}$ água se deslocassem para dentro e para fora do nanotubo. Uma vez atingido o equilíbrio, considerado quando a energia potencial do sistema oscila em torno de um valor constante, selecionamos a configuração de menor energia potencial total de cada caixa como a situação com o número ideal de moléculas de água no nanotubo.

Transferimos, então, o nanotubo - juntamente com as moléculas de surfactante e água em seu interior - para uma caixa de simulação vazia, ligando a extremidade do nanotubo à sua imagem periódica. Assim, a caixa de simulação se comporta como uma célula unitária de um feixe de nanotubos de comprimento infinito e seção transversal formando uma rede hexagonal, como se vê na Fig. 6.3.

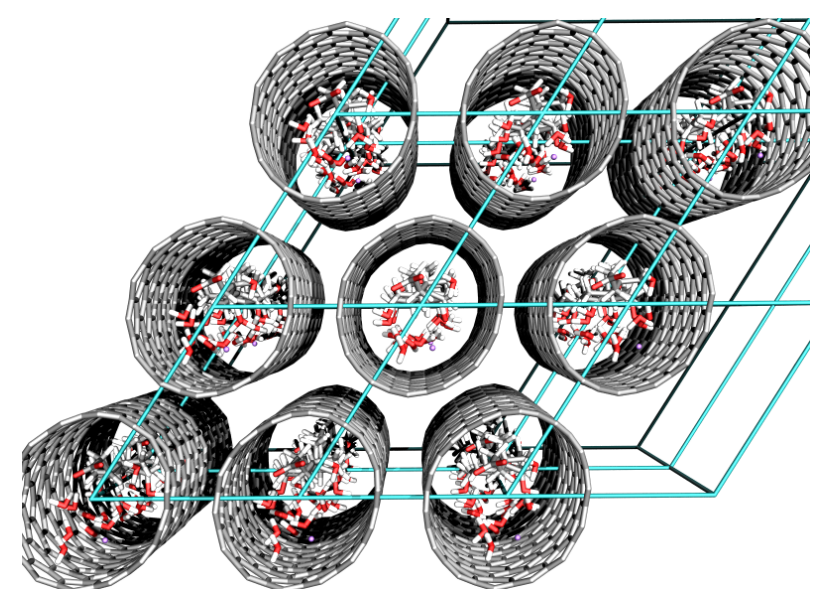

Figura 6.3: Exemplo de feixe hexagonal de nanotubos usado para calcular a densidade em estado sólido. Nanotubos $(14,0)$ preenchidos com SC e água.

O próximo passo foi otimizar a geometria do modelo, permitindo que parâmetros da célula unitária (três comprimentos e o ângulo no plano do papel na Fig. 6.3) variassem livremente para levar o sistema ao mínimo de energia. Essa liberdade paramétrica permitiu que o volume da célula variasse levando em conta uma região de exclusão em torno da superfície do nanotubo devido às forças de van der Waals entre os átomos de carbono e seus vizinhos. Consideramos a densidade dessa célula unitária, calculada diretamente como a massa de seu conteúdo dividida por seu volume, como a densidade do sistema em estado sólido.

Temos então dezoito valores de densidade, simulados para seis nanotubos diferentes, cada um deles em três casos: vazio, preenchido somente com água e preenchido com água e surfactante. Apresentamos esses dados graficamente na figura 6.4. 


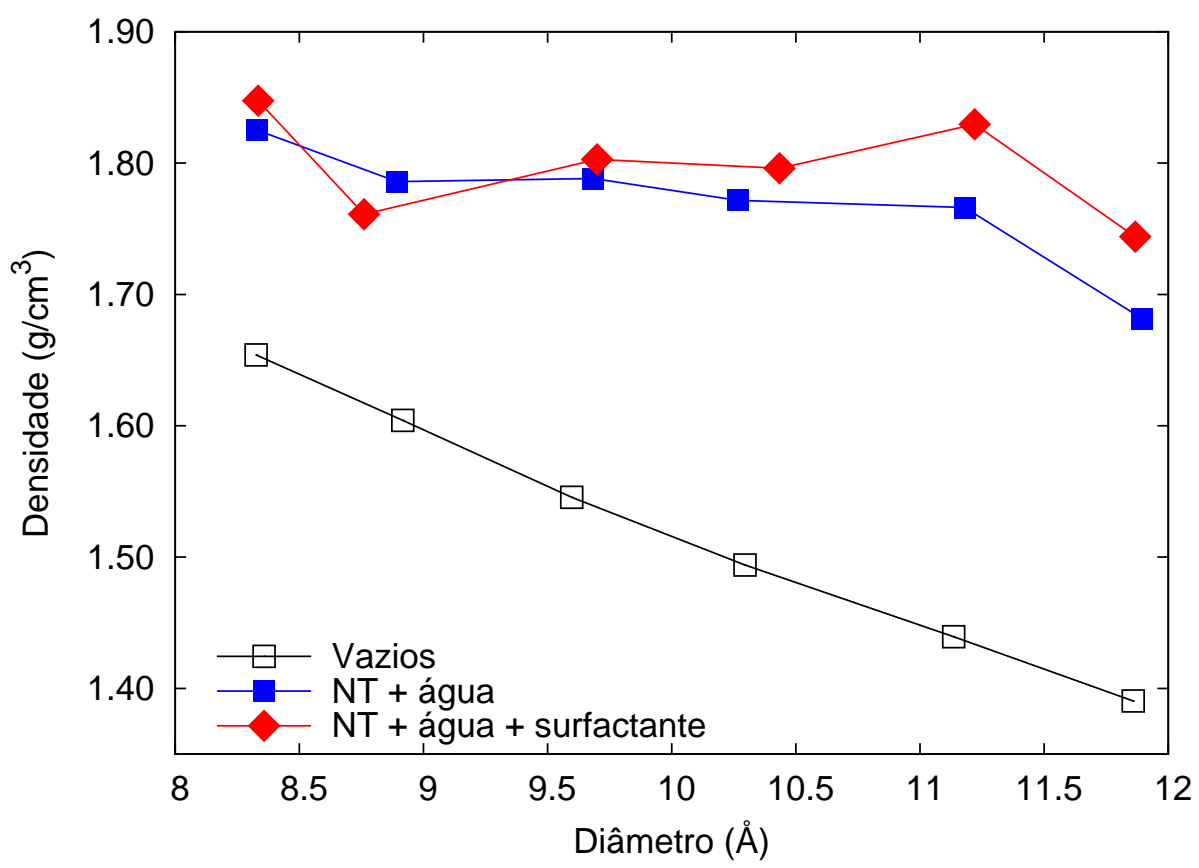

Figura 6.4: Densidade dos nanotubos simulada em estado sólido.

Observamos que, como previsto na equação (1.1), a densidade dos nanotubos vazios é monotonicamente decrescente em função do diâmetro, de forma coerente com o encontrado na literatura ${ }^{50}$. Entretanto, o preenchimento dos tubos, seja com apenas água, seja com água e surfactante faz com que esse comportamento decrescente seja atenuado, colocando nanotubos de vários diâmetros em uma faixa relativamente estreita de densidades.

Algo que se pode notar também é uma oscilação nos valores de densidade dos tubos preenchidos. Isso se deve ao tamanho dos tubos utilizados nas simulações e ao número de moléculas de água que tipicamente cabe em seu interior, tipicamente em torno de uma dezena. Assim, a entrada ou a saída de uma molécula de água dos tubos durante a simulação pode afetar em até $10 \%$ a densidade do conteúdo do nanotubo.

Outra coisa a observar é que, experimentalmente, o CNT não está, necessariamente, completamente preenchido com surfactante e água, de modo que os valores de densidade de tubo vazio e tubo preenchido são, respectivamente, os limites inferior e superior para a densidade medida. 


\subsection{Densidade em solução}

Com os valores da densidade em estado sólido em mãos, calculamos a densidade dos nanotubos na presença de uma camada de surfactante. Para isso, algumas aproximações foram necessárias. A primeira delas é considerar novamente o nanotubo como um cilindro ideal, com densidade média $\rho_{\text {solid }}$. Depois, consideramos a camada de surfactante como uma casca cilíndrica de densidade média $\rho_{\text {surf }}$ e espessura constante $t$ (Vide Figura 6.1). Determinamos a espessura $t$ dessa camada como a média das distâncias entre o nanotubo e o átomo mais distante no surfactante utilizando as simulações de dinâmica molecular a $1 \mathrm{~g} / \mathrm{cm}^{3}$ da Seção 4.3 .

Tendo essas aproximações em mente, calculamos a densidade linear (massa por unidade de comprimento) do nanotubo e da camada de surfactante para então obtermos a densidade do conjunto. Desse modo, a densidade linear do nanotubo será

$$
\lambda_{\text {solid }}=\pi \rho_{\text {solid }}(D / 2)^{2},
$$

onde $D$ é o diâmetro do tubo, calculado como a média dos parâmetros da rede hexagonal da figura 6.3, descontados $3,4 \AA$ do diâmetro de van der Waals do carbono. No caso da camada de surfactante, a densidade linear é obtida levando em conta a densidade do surfactante diluído e a área de uma casca circular de espessura $t$ e diâmetro interno $D$ :

$$
\lambda_{\text {surf }}=\pi \rho_{\text {surf }}\left[(D / 2+t)^{2}-(D / 2)^{2}\right] .
$$

Consideramos o valor de $\rho_{\text {surf }}$ como $1,01 \mathrm{~g} / \mathrm{cm}^{3}$, próximo à densidade da água, uma vez que a distribuição de moléculas em torno do nanotubo resulta em uma densidade menor que aquela da água ${ }^{52}$, de forma que a presença do surfactante nessa camada não deve mudar significativamente a densidade local. Medimos $t$ realizando otimização de geometria em segmentos dos nanotubos testados neste capítulo com um número variado de moléculas de SC ao seu redor. Consideramos o empacotamento com menor energia de ligação por molécula e medimos o diâmetro do sistema. Subtraindo disso o diâmetro do nanotubo, obtivemos $2 t \simeq 17 \AA$. Basta agora somar essas densidades lineares e dividir pela área total:

$$
\rho=\frac{\rho_{\text {solid }} D^{2}+\rho_{\text {surf }}\left[(D+2 t)^{2}-(D)^{2}\right]}{(D+2 t)^{2}} .
$$

Utilizando os dados da Fig. 6.4 e a equação (6.1), obtivemos os valores para a densidade dos nanotubos em solução dispostos na figura 6.5. 


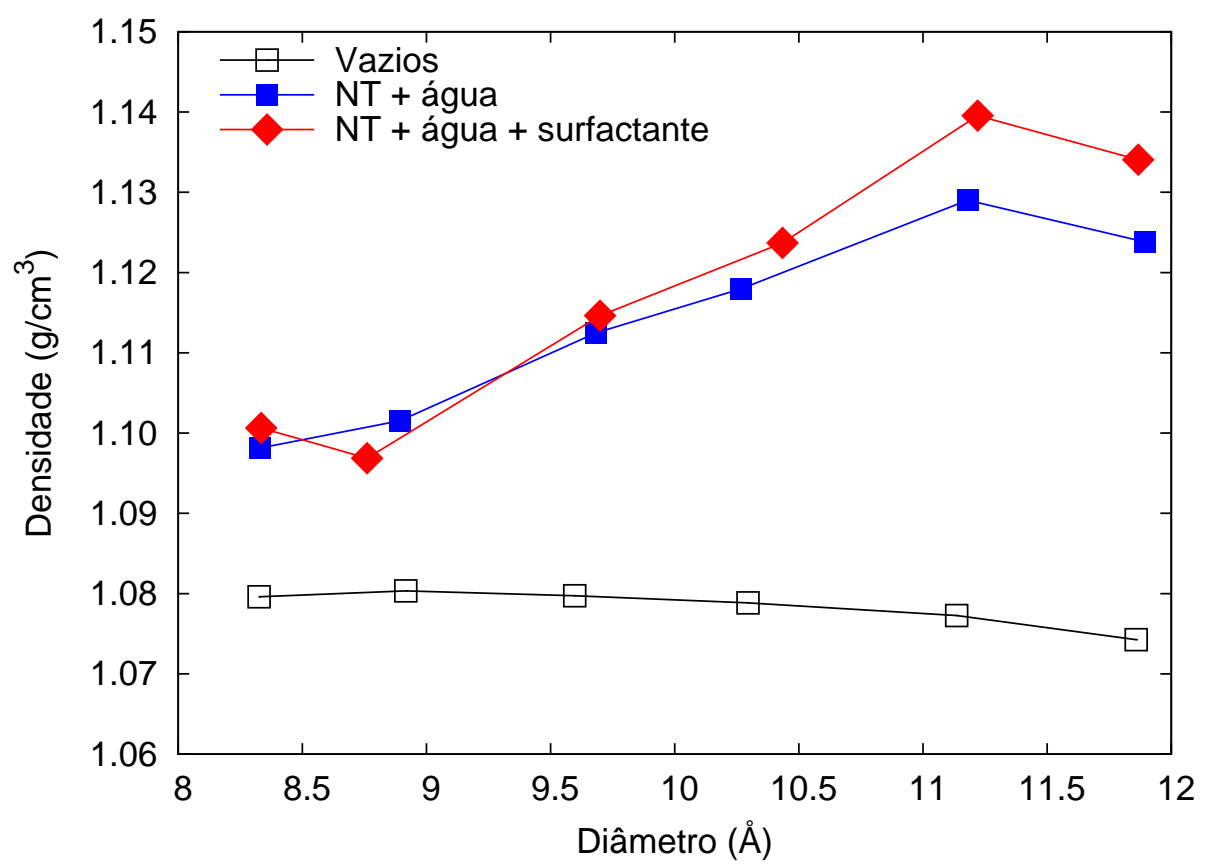

Figura 6.5: Densidade dos nanotubos calculada com a presença de uma camada de surfactante

Estes resultados nos mostram que as densidades dos nanotubos vazios se concentram numa faixa muito estreita, menor que $0,01 \mathrm{~g} / \mathrm{cm}^{3}$, mostrando que não é possível separar por gradiente de densidade nanotubos que não tenham sido preenchidos. Já olhando para as densidades dos tubos preenchidos observamos uma dependência crescente da densidade com o diâmetro, com-

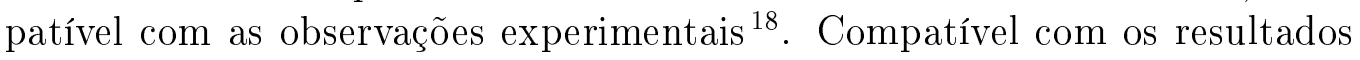
experimentais também são os valores das densidades, já que no trabalho de Arnold e colaboradores ${ }^{18}$ as frações de nanotubos selecionados se encontram entre $1,08 \mathrm{~g} / \mathrm{cm}^{3}$ e $1,15 \mathrm{~g} / \mathrm{cm}^{3}$.

Devemos nos lembrar da natureza hidrofóbica dos nanotubos ao interpretarmos os resultados envolvendo nanotubos preenchidos apenas com água. Como as simulações tiveram nanotubos preenchidos com água como condição inicial, não dão informação quanto à capacidade da água entrar nos tubos espontaneamente. Simulações de dinâmica (Vide seção 5.2) não indicaram tendência de moléculas de água entrarem nos nanotubos sem a presença de um surfactante. Por isso, deve-se esperar experimentalmente densidades menores para os nanotubos preenchidos apenas com água. 


\section{Capítulo 7}

\section{Conclusões}

Estudamos vários aspectos da interação de moléculas anfifílicas com nanotubos de carbono a fim de entendermos os fenômenos que levam nanotubos de carbono a se distribuírem em um gradiente de densidade de forma que tubos de maior diâmetro apresentem maior densidade que os de menor diâmetro, como reportado por Rinzler ${ }^{19}$ sobre o experimento realizado por Arnold e colaboradores 18 .

Nosso modelo de que moléculas de surfactante podem preencher os nanotubos e facilitar a entrada de moléculas de água em sua cavidade hidrofóbica nos levou a propor um novo surfactante para separar nanotubos em outra região de diâmetros. O surfactante proposto, MEN, é não-iônico e sua superfície hidrofóbica aromática interage mais fortemente com a parede do nanotubo. A grande flexibilidade de sua cadeia polar, em contrapartida, dificulta a presença da molécula no interior do tubo.

Notamos, entretanto, que tanto o SDS quanto o SC apresentam interação mais intensa com o interior do nanotubo que com sua superfície uma vez que o tubo apresente um diâmetro maior que um valor comparável com o raio de giração da molécula de surfactante. Juntamente com isso, surge a figura de diâmetros ótimos de nanotubo para cada surfactante, em que temos a interação mais intensa entre o tubo e a anfifila, chegando a $80 \mathrm{kcal} / \mathrm{mol} \mathrm{em}$ favor da molécula no interior da cavidade perante o caso em que ela se adere à superfície da estrutura.

O próximo passo foi avaliar o efeito do solvente — água — nessa interação e observamos que a água pode inverter a estabilidade relativa entre o SDS e nanotubos de diâmetros maiores, mas não altera significativamente o comportamento nos casos em que o surfactante interage com nanotubos com diâmetro próximo de seu diâmetro ótimo. Com isso entendemos que os surfactantes ainda encontram sua posição mais favorável no interior de tubos com diâmetro adequado. 
Verificamos através de dinâmica molecular que é possível que a molécula entre na cavidade, sobrepujando alguma possível barreira energética na boca do tubo, transmitindo sua energia cinética para os modos vibracionais do nanotubo e ficando presa em uma espécie de poço de potencial no interior da cavidade.

Em meio aquoso, moléculas do surfactante continuam sendo atraídas para o interior do nanotubo, arrastando consigo moléculas de água vizinhas, que passam a preeencher o nanotubo e aumentar sua densidade. Notamos também que moléculas de água não são atraídas para dentro do tubo na ausência de surfactantes, evidenciando mais uma vez a importância dessas substâncias no processo de separação.

Finalmente, calculamos o efeito que a presença dessas substâncias nos nanotubos tem na densidade de uma amostra. Desenvolvemos um protocolo para determinar a densidade de um nanotubo levando em conta possíveis deformações causadas pelo conteúdo da cavidade. Observamos com isso que o preenchimento dos nanotubos de fato compensa a relação inversa entre diâmetro e densidade de nanotubos, mas não é suficiente para explicar o resultado experimental.

A existência de uma camada de surfactante envolvendo cada nanotubo é responsável pelo debundling de feixes de nanotubos e deve ser levada em conta no cálculo da densidade. Ao fazermos isso analiticamente, observamos que essa camada torna nanotubos vazios inseparáveis por gradiente de densidade, já que eles acabam se distribuindo numa faixa muito estreita de densidade. Nanotubos preenchidos, entretanto, passam a ter densidades que crescem quando o diâmetro aumenta, como observado experimentalmente.

Mostramos, assim, que o surfactante desempenha um papel fundamental na separação de nanotubos de carbono por gradiente de densidade por ser capaz de entrar em nanotubos de diâmetro adequado e preenchê-los com água e por formar uma camada em torno dos nanotubos, permitindo que os feixes se separem em tubos isolados. É essa ação conjunta, no interior e exterior do nanotubo, a responsável pelo sucesso desse método não destrutivo de separação por diâmetro.

Notamos ainda que esse método de separação por diâmetro, até o momento, foi bem sucedido em isolar nanotubos de diâmetro menor que $11 \AA$, apesar de as amostras conterem tubos maiores. De acordo com nosso modelo, a separação de nanotubos maiores requer a utilização de um surfactante que apresente o diâmetro ótimo, como calculado no Capítulo 4, em regiões superiores, como $13 \AA$ ou $15 \AA$. Por isso, este trabalho deixa como proposta a busca de moléculas anfifílicas com raio de giração maior que o do SC para viabilizar a separação de nanotubos de diâmetro maior. 


\section{Apêndice A}

\section{Mecânica Molecular: Teoria}

Um sistema de partículas interagindo na escala atômica pode ser descrita por uma função de onda $\Psi$ determinada pela equação de Schrödinger

$$
H \Psi(\mathbf{R}, \mathbf{r})=E \Psi(\mathbf{R}, \mathbf{r})
$$

onde $H$ é o operador hamiltoniano que contém as informações sobre as interações entre as partículas, $\mathbf{R}$ são as coordenadas dos núcleos atômicos e $\mathbf{r}$ são as coordenadas dos elétrons. Essa equação apresenta grande complexidade, portanto algumas aproximações se fazem necessárias.

A primeira delas envolve separar a função de onda total em uma parte eletrônica e uma parte nuclear $\stackrel{53}{ }$.

$$
\Psi(\mathbf{R}, \mathbf{r})=\psi(\mathbf{r} ; \mathbf{R}) \Phi(\mathbf{R})
$$

onde $\psi(\mathbf{r} ; \mathbf{R})$ é a função de onda eletrônica, que depende explicitamente das coordenadas eletrônicas, mas apenas parametricamente das coordenadas nucleares e $\Phi(\mathbf{R})$ é a função de onda nuclear. Essa separação é realizada separando-se os termos da hamiltoniana dependentes das coordenadas eletrônicas e os dependentes das coordenadas nucelares:

$$
\begin{aligned}
H_{\mathrm{el}} & =T_{\mathrm{el}}+V_{\mathrm{el}-\mathrm{N}}+V_{\mathrm{el}-\mathrm{el}} \\
H_{\mathrm{N}} & =T_{\mathrm{N}}+V_{\mathrm{N}-\mathrm{N}} \\
H & =H_{\mathrm{N}}+H_{\mathrm{el}},
\end{aligned}
$$

de modo a termos duas equações:

$$
\begin{aligned}
H_{\mathrm{el}} \psi(\mathbf{r} ; \mathbf{R}) & =E_{\mathrm{el}}(\mathbf{R}) \psi(\mathbf{r} ; \mathbf{R}) \mathrm{e} \\
\left(H_{\mathrm{N}}+E_{\mathrm{el}}(\mathbf{R})\right) \Phi(\mathbf{R}) & =E \Phi(\mathbf{R}) .
\end{aligned}
$$


Justificamos a separação dos termos da hamiltoniana dependentes apenas das coordenadas nucleares através do fato de que a massa dos elétrons é milhares de vezes menor que a massa dos núcleos. Com isso, os elétrons adaptam-se rapidamente a mudanças nas coordenadas nucleares que podem, portanto, ser consideradas parâmetros a serem fixados para a solução da equação (A.1).

A equação para a função de onda eletrônica (A.1) nos dá uma energia que depende das coordenadas nucleares $E_{\text {el }}(\mathbf{R})$. Essa energia pode ser considerada uma energia potencial para o movimento dos núcleos devido à rapidez do ajuste de $\psi(\mathbf{r} ; \mathbf{R})$ ao movimento nuclear. Incorporamos esse potencial à repulsão núcleo-núcleo $V_{\mathrm{N}-\mathrm{N}}$ e obtemos a equação de Schrödinger para os núcleos (A.2).

Existem três tipos de abordagem para resolver as equações (A.1) e (A.2). Os métodos $a b$ initio resolvem diretamente as integrais necessárias através de teorias de Hartree-Fock, de funcional da densidade eletrônica ou de perturbação. Métodos semiempíricos simplificam a resolução da (A.1) utilizando tabelas de valores parametrizados a partir de cálculos mais sofisticados ou resultados experimentais. Técnicas de mecânica molecular eliminam inteiramente o problema de resolver as equações de autovalores obtendo os valores da energia potencial $E_{\mathrm{el}}(\mathbf{R})$ de tabelas conhecidas como campos de força e considerando os núcleos como pontos materiais clássicos para os quais vale a equação de movimento de Newton.

Cada abordagem apresenta suas vantagens e limitações. Enquanto os métodos ab initio levam a resultados mais detalhados, com informações sobre densidade eletrônica, possíveis quebras de ligação e estados excitados, são computacionalmente onerosos, tanto em termos de tempo de processamento quanto de memória. Sua aplicação, portanto, se torna inviável para sistemas com mais de algumas dezenas de átomos. Métodos semiempíricos são menos custosos mas, como todo método parametrizado, está sujeito à escolha de um conjunto adequado de parâmetros e ainda dependem de cálculos autoconsistentes, que demandam bastante tempo de processamento.

Neste capítulo vamos nos concentrar em mecânica molecular, a técnica utilizada para realizar as simulações aqui relatadas. Métodos clássicos são menos complexos computacionalmente entretanto necessitam informações como a carga elétrica em cada átomo e as ligações químicas do modelo na forma de parâmetros de entrada. 


\section{A.1 Campos de força}

Em mecânica molecular clássica entendemos os núcleos atômicos como pontos materiais dotados de massa e carga elétrica que interagem sob um potencial $V(\mathbf{r})$ e obedecem às equações de movimento

$$
\mathbf{F}=-\frac{\partial V}{\partial \mathbf{r}}=m_{i} \frac{\partial^{2} \mathbf{r}}{\partial t^{2}}
$$

O potencial $V(\mathbf{r})$ tem o mesmo papel da energia eletrônica da separação de Born-Oppenheimer $E_{\mathrm{el}}(\mathbf{R})$ associada à repulsão núcleo-núcleo $V_{\mathrm{N}-\mathrm{N}}$. Para determinar o potencial $V(\mathbf{r})$ de um sistema em particular utiliza-se um conjunto de parâmetros ${ }^{54}$, provenientes de cálculos mais sofisticados ou de resultados experimentais, conhecido como campo de força:

Tipo atômico consiste em informações como o elemento químico, o tipo de ligações que ele faz e sua carga líquida;

Regras de definição de tipo atômico atribuem a cada átomo do modelo um tipo atômico de acordo com o elemento químico e as ligações que efetua;

Formas funcionais de interação definem a forma da energia potencial baseada no tipo de interação entre os átomos;

Parâmetros de interação dependem dos tipos atômicos envolvidos e determinam o valor numérico da energia potencial.

Uma simulação de mecânica molecular inicia com um modelo com a geometria aproximada do sistema e informações sobre os elementos envolvidos e as ligações químicas entre eles, definidas pelo usuário. Aqui surge uma das limitações da mecânica molecular, já que a energia do sistema depende das ligações químicas previamente definidas, de forma que fenômenos como quebras de ligação não são obtidos espontaneamente.

Uma vez definidos os dados do modelo, o próximo passo consiste em calcular a expressão de energia com base nas formas funcionais do campo de força e nas interações do modelo. Uma expressão de energia se parece com

$$
V=V_{\text {ligação }}+V_{\text {ângulo }}+V_{\text {torção }}+V_{\text {inversão }}+V_{\text {cruzado }}+V_{\text {vdW }}+V_{\text {Coulomb }} .
$$

Cada termo tem sua origem em um tipo de interação entre pares, trios e quartetos de átomos, ligados ou não. $V_{\text {Coulomb }}$, por exemplo, é proveniente da interação eletrostática entre pares de átomos carregados. 
O próximo termo mais simples, $V_{\mathrm{vdw}}$, representa a interação de van der Waals entre pares de átomos na forma

$$
V_{\mathrm{vdW}}=\sum_{\substack{i, j \\ i<j}} \epsilon_{i j}\left[\left(\frac{r_{i j}^{*}}{r_{i j}}\right)^{12}-2\left(\frac{r_{i j}^{*}}{r_{i j}}\right)^{6}\right],
$$

onde $\epsilon_{i j}$ é o parâmetro de Lennard-Jones entre os átomos $i$ e $j$ e $r_{i j}^{*}$ é a distância de equilíbrio dos átomos $i$ e $j$ na ausência de outros termos. Como a força de van der Waals é menos intensa que as forças de ligação, este termo não é calculado para pares de átomos ligados entre si (primeiros vizinhos) ou ligados a um átomo em comum (segundos vizinhos). A aplicação deste termo para terceiros vizinhos depende da forma com que o campo de força é parametrizado e costuma vir acompanhada de um fator multiplicativo. O mesmo tipo de restrição de vizinhos é feito quando se considera a o termo eletrostático.

Outro termo que envolve pares de átomos está relacionado às ligações

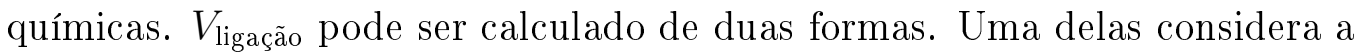
ligação equivalente a uma mola e tem a forma de um potencial harmônico:

$$
V_{\text {ligação }}=\sum_{i, j \text { ligados }}^{i<j} K_{i j}\left(r_{i j}-r_{i j}^{*}\right)^{2} .
$$

Outra, conhecida como potencial de Morse, melhora aproximação harmônica fazendo com que a energia de interação vá a zero quando a distância vai ao infinito, como observado em métodos mais sofisticados:

$$
V_{\text {ligação }}=\sum_{i, j} D_{i<j}\left[1-e^{-\alpha_{i j}\left(r_{i j}-r_{i j}^{*}\right)}\right]^{2} .
$$

Esta forma funcional é útil quando se deseja levar em conta termos anarmônicos em eventos como possíveis quebras de ligação ou deformações moleculares em condições extremas. Deve ser aplicado com cuidado, pois em condições de alta energia podem levar a configurações pouco realistas $\underline{54}$.

O termo seguinte envolve três átomos e está relacionado ao ângulo entre as ligações de dois átomos com um átomo em comum. Se $\widehat{i k j}$ for o ângulo centrado no átomo $k$ formado entre os átomos $i$ e $j$, esse termo, harmônico, será dado por

$$
V_{\text {ângulo }}=\sum_{\widehat{i k j}} H_{\widehat{i k j}}\left(\theta_{\widehat{i k j}}-\theta_{\widehat{i k j}}^{*}\right)^{2} .
$$


Também é possível definir esse termo como harmônico nos cossenos dos ângulos, de forma que

$$
V_{\text {ângulo }}=\sum_{\widehat{i k j}} H_{\widehat{i k j} j}\left(\cos \theta_{\widehat{i k j}}-\cos \theta_{\overparen{i k j}}^{*}\right)^{2} .
$$

Termos relacionados a quartetos de átomos podem envolver átomos encadeados ligados dois a dois ou um átomo ligado a três outros. No primeiro caso, temos as torçôes: a cadeia de átomos $i-j-k-l$ pode torcer em torno da ligação $j-k$, de modo a mudar o ângulo $\phi$ formado pelos planos $i j k$ e $j k l$ (vide fig. A.1(a)). O termo energético pode ser harmônico no cosseno do ângulo $\omega$ :

$$
V_{\text {torção }}=\sum_{\text {torções }} C\left(\cos \omega-\cos \omega^{*}\right)^{2},
$$

harmônico no ângulo w:

$$
V_{\text {torção }}=\sum_{\text {torções }} K_{\omega}\left(\omega-\omega^{*}\right)^{2}
$$

ou periódico, com período $n$

$$
V_{\text {torção }}=\sum_{\text {torções }} K_{\omega}\left(1-B_{\omega}(-1)^{n} \cos n \omega\right) .
$$

No segundo caso, chamado de inversão, temos o átomo $i$ ligado a três outros átomos, $j, k$ e $l$. Há três formas de calcular a energia relacionada às inversões 5 :

Umbrella: O átomo central $i$ forma um plano juntamente com os átomos $j$ e $k$. O cosseno ângulo $\omega$ entre esse plano e a ligação $i-l$ é considerado harmonicamente: $V_{\text {inversão }}=\sum_{\text {inversões }} K_{\omega}\left(\cos \omega-\cos \omega^{*}\right)^{2}$. Fig A.1(b),

Torção imprópria $j i l k$ : A ligação $i-l$ forma o eixo de uma torção e o ângulo entre os planos jil e ilk é tratado como um grau de liberdade do sistema (Fig A.1(c)]. A energia, nesse caso, una função periódica $V_{\text {inversão }}=\sum_{\text {inversões }} K_{\omega}\left[1-\cos \left(n\left(\omega-\omega^{*}\right)\right)\right]$, onde $n$ é o número de mínimos de energia ao longo da torção;

Torção imprópria $i j k l$ : Neste caso, os planos levados em conta são $j k l$ e $i j k$, definidos pelos três átomos ligados ao átomo central e pelo átomo central e dois periféricos, como na Fig. A.1(d). O ângulo entre esses planos é tratado harmonicamente: $V_{\text {inversão }}=\sum_{\text {inversões }} K_{\omega}\left(\omega-\omega^{*}\right)^{2}$. 


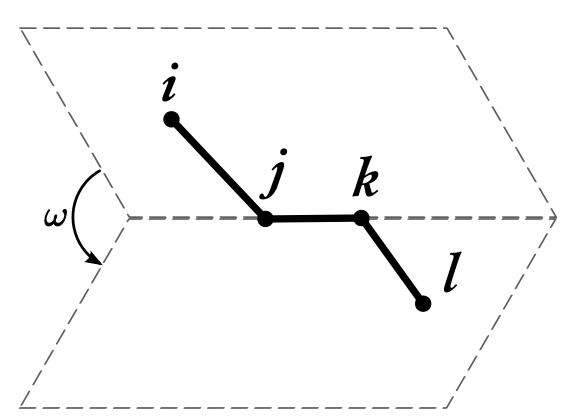

(a) Torção

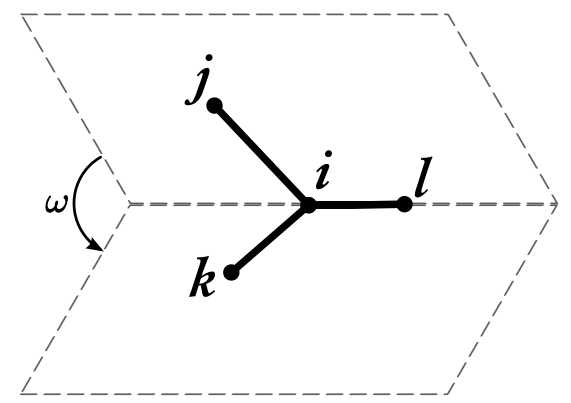

(c) Torção imprópria jilk

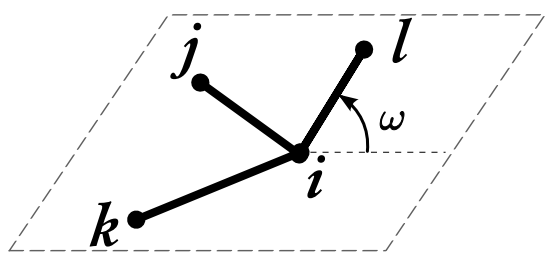

(b) Inversão umbrella

Figura A.1: Tipos de torção e inversão. $\omega$ é o ângulo de torção ou inversão. Figuras tracejadas esmaecidas representam os planos entre os quais $\omega$ é calculado.

A escolha da forma funcional dos termos de inversão depende da parametrização do campo de força. Entretanto, dados quatro átomos que podem formar uma inversão há três inversões possíveis, oriundas das permutações entre os átomos $j k l$. Novamente, a decisão sobre qual das três inversões considerar depende da implementação particular do campo de força e usualmente consiste em adotar a primeira torção encontrada ou a média aritmética das três torções possíveis. $\frac{54}{\text {. }}$.

Existem também os termos cruzados, que envolvem pares de ligações, pares de ângulos entre três ligações, comprimentos de ligações e torções etc. Esses termos aparecem em campos de força mais sofisticados para melhor ajustar resultados experimentais.

Através dessas relações de energia, dos parâmetros tabelados no campo de força e da descrição do modelo, com coordenadas, cargas e posições é possível calcular a energia do sistema para uma dada geometria. Dois métodos utilizam essa informação energética: otimização de geometria e dinâmica molecular. 


\section{A.2 Otimização de geometria}

Otimizar a geometria de um sistema significa procurar sua configuração de equilíbrio, ou seja, aquela em que a força nos átomos seja nula e a energia do sistema seja um mínimo. Para tanto, utilizamos os chamados algoritmos de minimização.

A maioria desses algoritmos faz uso do conceito de busca linear, que consiste em reduzir a busca por um mínimo em um espaço multidimensional para uma linha, unidimensional. Fazemos isso definindo uma direção de busca $\mathbf{h}(\alpha)$, dependente do gradiente da energia

$$
\mathbf{h}(\alpha)=\mathbf{r}_{0}-\left.\alpha \nabla E(\mathbf{r})\right|_{\mathbf{r}=\mathbf{r}_{0}}
$$

e calculando sistematicamente o valor de $E(\mathbf{h}(\alpha))$ para diversos valores de $\alpha$ em busca de um mínimo. Quando encontram um mínimo na direção $\mathbf{h}$, repetimos iterativamente o processo, alimentando com o ponto de mínimo recém-localizado $\mathbf{r}_{i}$ a equação (A.4), até que o gradiente de energia seja menor que um certo valor de tolerância, quando dizemos que o processo convergiu.

A etapa mais demorada desse procedimento é o cálculo de $E(\mathbf{r})$, portanto a velocidade do algoritmo pode ser melhorada quando eliminamos a busca sistemática por um mínimo na direção $\mathbf{h}(\alpha)$. Em vez disso, podemos aceitar uma iteração se $E(\mathbf{h}(\alpha))<E\left(\mathbf{r}_{0}\right)$. Caso contrário, realizamos uma tentativa com um passo $\alpha$ menor até que a condição seja satisfeita. Apesar de obtermos convergência em um número aproximadamente igual de iterações $\frac{54}{}$, cada iteração exige menos cálculos de energia e o processo se mostra mais eficiente.

Esse método, conhecido como descida mais ingreme ${ }^{1}$, entretanto, utiliza apenas a informação do gradiente no ponto atual para determinar a nova direção de busca pelo mínimo. Um modo de utilizar informação obtida anteriormente consiste no método do gradiente conjugad $\delta^{2}$, em que a nova direção de busca $\mathbf{h}_{i+1}$ é calculada com base no gradiente da energia e na direção de busca anterior:

$$
\mathbf{h}_{i+1}=\nabla E\left(\mathbf{r}_{i+1}\right)+\gamma_{i} \mathbf{h}_{i} .
$$

O fator $\gamma_{i}$ pode ser calculado relacionando o gradiente atual com o anterior ${ }^{54}$

$$
\gamma_{i}=\frac{\nabla E\left(\mathbf{r}_{i+1}\right) \cdot \nabla E\left(\mathbf{r}_{i+1}\right)}{\nabla E\left(\mathbf{r}_{i}\right) \cdot \nabla E\left(\mathbf{r}_{i}\right)},
$$

de forma que o gradiente $E\left(\mathbf{r}_{i+1}\right)$ não só é ortogonal à direção de busca anterior como a todos os gradientes anteriores, evitando que se desperdice tempo de cálculo em trajetórias de ziguezague em torno da direção do mínimo.

\footnotetext{
${ }^{1}$ Steepest descent, em inglês

${ }^{2}$ Conjugate gradient, em inglês
} 
Caso o ponto de partida esteja suficientemente próximo do mínimo a ponto de a superfície de energia poder ser considerada parabólica, podemos utilizar a informação da curvatura do potencial para acelerar a busca pelo mínimo. Para isso, utilizamos a inversa da matriz Hessiana $\mathbb{A}(\mathbf{R})$, que contém informações sobre as segundas derivadas do potencial para estimar o próximo ponto de mínimo:

$$
\mathbf{r}_{i+1}=\mathbf{r}_{i}+\mathbb{A}^{-1}\left(\mathbf{r}_{i}\right) \nabla E\left(\mathbf{r}_{i}\right) .
$$

A aplicação desse procedimento em mecânica molecular encontra empecilhos devido à complexidade de se calcular a matriz hessiana e sua inversa em sistemas com grande número de coordenadas. Além disso, a suposição de potencial parabólico só é válida em configurações muito próximas do mínimo. Métodos do tipo Newton-Raphson como este só são aplicados caso seja necessária uma convergência muito fina e somente após uma otimização inicial utilizando outros métodos. 


\section{Apêndice B}

\section{Dinâmica Molecular: Teoria}

Utilizamos a dinâmica molecular para calcular a evolução temporal de um sistema molecular e com ela montarmos trajetórias desse sistema no espaço de fase. Devido ao grande número de átomos envolvidos nas simulações deste trabalho, fizemos uso da dinâmica molecular clássica, em que integramos as equações de movimento de Newton

$$
\mathbf{F}_{i}(t)=m_{i} \mathbf{a}_{i}(t),
$$

onde $\mathbf{F}_{i}$ é a força, $m_{i}$ é a massa e $\mathbf{a}_{i}$ é a aceleração do átomo $i$. A força sobre cada átomo é determinada pelo campo de força - conjunto de funções de energia potencial de interação entre átomos - adotado, através de uma diferenciação em função das coordenadas $\mathbf{r}_{\mathbf{i}}$, de modo que a equação de movimento se torna

$$
-\frac{\partial V}{\partial \mathbf{r}_{i}}=m_{i} \frac{\partial^{2} \mathbf{r}_{i}}{\partial t^{2}}
$$

Temos, então, um conjunto de equações diferenciais que podem ser resolvidas por métodos de diferenças finitas, em que, dadas as coordenadas e as velocidades dos átomos no instante $t$, podemos calcular diretamente essas variáveis no instante $t+\Delta t$.

O método empregado no pacote Cerius $^{2}$ é do tipo Verlet ${ }^{54}$, que pode ser deduzido da expansão de Taylor para a posição da partícula nos instantes $t \pm \Delta t$ :

$$
\begin{aligned}
& \mathbf{r}(t+\Delta t)=\mathbf{r}(t)+\mathbf{v}(t) \Delta t+\frac{\mathbf{F}(t)}{2 m} \Delta t^{2}+\frac{\Delta t^{3}}{3 !} \dddot{\mathbf{r}}+O\left(\Delta t^{4}\right) \mathrm{e} \\
& \mathbf{r}(t-\Delta t)=\mathbf{r}(t)-\mathbf{v}(t) \Delta t+\frac{\mathbf{F}(t)}{2 m} \Delta t^{2}-\frac{\Delta t^{3}}{3 !} \dddot{\mathbf{r}}+O\left(\Delta t^{4}\right)
\end{aligned}
$$


onde omitimos os índices dos átomos $i$ por simplicidade. Somando as equações $(\underline{B .3})$ e (B.4) e isolando $\mathbf{r}(t+\Delta t)$ temos

$$
\mathbf{r}(t+\Delta t)=2 \mathbf{r}(t)-\mathbf{r}(t-\Delta t)+\frac{\mathbf{F}(t)}{m} \Delta t^{2}+O\left(\Delta t^{4}\right),
$$

ou seja, obtemos as posições atômicas seguintes com um erro da ordem $\Delta t^{4}$ utilizando as posições atuais, anteriores e as forças sobre os átomos. Uma vez que esse algoritmo não utiliza a velocidade, esta grandeza deve ser calculada separadamente.

Um modo é calcular a velocidade em um ponto intermediário entre um passo e outro 56 .

$$
\begin{aligned}
& \mathbf{v}(t-\Delta t / 2)=\frac{\mathbf{r}(t)-\mathbf{r}(t-\Delta t)}{\Delta t} \\
& \mathbf{v}(t+\Delta t / 2)=\frac{\mathbf{r}(t+\Delta t)-\mathbf{r}(t)}{\Delta t}
\end{aligned}
$$

isso significa que devemos calcular as posições atualizadas $\mathbf{r}(t+\Delta t)$ para sabermos a velocidade $\mathbf{v}(t+\Delta t / 2)$. Podemos, entretanto, utilizar a equação (B.7) para calcular as posições atualizadas

$$
\mathbf{r}(t+\Delta t)=\mathbf{r}(t)+\mathbf{v}(t+\Delta t / 2) \Delta t
$$

se calcularmos a velocidade intermediária como

$$
\mathbf{v}(t+\Delta t / 2)=\mathbf{v}(t-\Delta t / 2)+\Delta t \frac{\mathbf{F}(t)}{m}
$$

de modo que os valores conhecidos de velocidade e posição dos átomos são conhecidos para intervalos de tempo alternados, como crianças pulando em uma brincadeira de pula-sela (leapfrog em inglês). Por isso este algoritmo é conhecido como Leapfrog. Uma desvantagem desse algoritmo é o fato de sempre termos as informações sobre velocidade e posição defasadas de $\Delta t / 2$,

Pula-sela (Leapfrog) 57 entretanto é simples ${ }^{58}$ calcular $\mathbf{v}(t)$ :

$$
\mathbf{v}(t)=\frac{\mathbf{v}(t+\Delta t / 2)+\mathbf{v}(t-\Delta t / 2)}{2}
$$

Dados valores adequados de $\Delta t$, o algoritmo resulta em boa conservação de energia no curto prazo (na ordem de dezenas de passos de integração) e apresenta um desvio energético muito baixo em longo prazo (milhares de $\operatorname{passos})^{56}$. 


\section{B.1 Mantendo a temperatura constante}

Uma vez que o algoritmo Leapfrog conserva razoavelmente a energia, a estatística de um sistema dinâmico simulado com ele é microcanônica. Por outro lado, sistemas físicos costumam estar em contato com um banho térmico, de modo que devemos buscar métodos capazes de reproduzir a estatística de um ensemble canônico a uma dada temperatura $T$.

Como o algoritmo não faz referência à temperatura do sistema, ela deve ser calculada a partir da velocidade dos átomos:

$$
k_{B} T=\frac{2}{g_{T}} \sum_{i=1}^{N} \frac{m_{i} \mathbf{v}_{i}^{2}}{2}=\frac{1}{g_{T}} \sum_{i=1}^{N} K_{i}
$$

onde $K_{i}$ é a energia cinética da partícula $i, k_{B}$ é a constante de Boltzmann e $g_{T}$ é um fator que depende do número de graus de liberdade do sistema, com $g_{T}=3 N-6$ para sistemas não periódicos e $g_{T}=3 N-3$ para sistemas periódicos, levando em conta que graus de liberdade de translação e, no caso de sistemas periódicos, também os graus de rotação, não devem influenciar a temperatura.

Uma forma simples e um tanto ingênua de manter a temperatura dentro de uma região aceitável é manipular a energia cinética das partículas multiplicando diretamente as velocidades de modo que ${ }^{54}$

$$
\left(\frac{v_{\text {novo }}}{v_{\text {antigo }}}\right)^{2}=\frac{T_{\text {alvo }}}{T_{\text {sistema }}}
$$

entretanto esse tipo de correção artificial não é capaz de reproduzir a estatística de um ensemble canônico $\frac{56}{}$.

Berendsen et al. ${ }^{59}$ sugerem a introdução de um tempo de relaxação $\tau$ ao longo do qual o sistema troca energia com um banho térmico. Essa troca mais suave de energia pode ser implementada multiplicando a velocidade das partículas por

$$
\lambda=\left[1+\frac{\Delta t}{\tau}\left(\frac{T_{\text {alvo }}}{T_{\text {sistema }}}-1\right)\right]^{1 / 2},
$$

justificada pela inserção de termos estocásticos e de arrasto na equação de movimento. Essa abordagem, entretanto, não é reversível no tempo ${ }^{47}$.

Quando se busca um comportamento determinístico e reversível, é mais conveniente utilizar uma abordagem de hamiltoniana estendida, proposta por S. Nosé ${ }^{58}$ e reformulada por W.G. Hoover ${ }^{47}$, em que uma coordenada $s$, relacionada à interação do sistema com um reservatório térmico, e seu 
momento $p_{s}$, são adicionadas à hamiltoniana do sistema:

$$
\mathcal{H}=\sum_{i=1}^{N} \frac{1}{2 m_{i}} \frac{\mathbf{p}_{i}^{2}}{s^{2}}+V(\{\mathbf{r}\})+\frac{p_{s}^{2}}{2 Q}+k_{B} T g \ln s
$$

considerando $Q$ uma massa fictícia associada à troca de energia entre o sistema e o reservatório e $g$ está associado ao número de graus de liberdade do sistema.

Dessa forma, temos as equações de movimento dadas por

$$
\begin{aligned}
\frac{\mathrm{d} \mathbf{r}_{i}}{\mathrm{~d} t} & =\frac{\partial \mathcal{H}}{\partial \mathbf{p}_{i}}=\frac{\mathbf{p}_{i}}{m_{i} s^{2}} \\
\frac{\mathrm{d} \mathbf{p}_{i}}{\mathrm{~d} t} & =-\frac{\partial \mathcal{H}}{\partial \mathbf{r}_{i}}=-\frac{\partial V(\{\mathbf{r}\})}{\partial \mathbf{r}_{i}} \\
\frac{\mathrm{d} s}{\mathrm{~d} t} & =\frac{\partial \mathcal{H}}{\partial p_{s}}=\frac{p_{s}}{Q} \\
\frac{\mathrm{d} p_{s}}{\mathrm{~d} t} & =-\frac{\partial \mathcal{H}}{\partial s}=\frac{1}{s}\left(\sum_{i=1}^{N} \frac{\mathbf{p}_{i}^{2}}{m_{i} s^{2}}-k_{B} T g\right)
\end{aligned}
$$

Podemos definir um momento dimensionado $\mathbf{p}^{\prime}=\mathrm{p} / s$, de modo que se fizermos a estatística no espaço de fase dado por $\mathbf{p}^{\prime}$ e $\mathbf{r}$ é possível mostrar ${ }^{56}$ que recuperamos o ensemble canônico $(N V T)$. Pelo seu papel no espaço de fase, podemos considerar $\mathbf{p}^{\prime}$ o momento real do sistema. Vamos então definir variáveis correspondentes a esse espaço de fase e chamá-las de variáveis reais:

$$
\begin{aligned}
\mathbf{r}^{\prime} & =\mathbf{r} \\
\mathbf{p}^{\prime} & =\mathbf{p} / s \\
s^{\prime} & =s \\
\Delta t^{\prime} & =\Delta t / s .
\end{aligned}
$$

Com isso, vemos que $s$ pode ser considerado um fator de dimensionamento de tempo. Como passos temporais variáveis são complicados de analisar em mecânica molecular, vamos reescrever as equações de movimento para utilizar 
as variáveis reais:

$$
\begin{aligned}
\frac{\mathrm{d} \mathbf{r}_{i}^{\prime}}{\mathrm{d} t^{\prime}} & =s \frac{\mathrm{d} \mathbf{r}_{i}}{\mathrm{~d} t}=\frac{\mathbf{p}_{i}^{\prime}}{m_{i}} \\
\frac{\mathrm{d} \mathbf{p}_{i}^{\prime}}{\mathrm{d} t^{\prime}} & =s \frac{\mathrm{d} \mathbf{p}_{i}}{\mathrm{~d} t}-\frac{1}{s} \mathbf{p}_{i} \frac{\mathrm{d} s}{\mathrm{~d} t}=-\frac{\partial V\left(\left\{\mathbf{r}^{\prime}\right\}\right)}{\partial \mathbf{r}_{i}^{\prime}}-\left(\frac{s^{\prime} p_{s}^{\prime}}{Q}\right) \mathbf{p}_{i}^{\prime} \\
\frac{\mathrm{d} s^{\prime}}{\mathrm{d} t^{\prime}} & =s \frac{\mathrm{d} s}{\mathrm{~d} t}=\frac{s^{\prime} p_{s}^{\prime}}{Q} \\
\frac{\mathrm{d} s^{\prime} p_{s}^{\prime} / Q}{\mathrm{~d} t^{\prime}} & =\frac{s}{Q} \frac{\mathrm{d} p_{s}}{\mathrm{~d} t}=\frac{1}{Q}\left(\sum_{i=1}^{N} \frac{\mathbf{p}_{i}^{2}}{m_{i} s^{2}}-k_{B} T g\right),
\end{aligned}
$$

dessa forma isolamos as variáveis associadas ao reservatório térmico $s^{\prime}, p_{s}^{\prime}$ e $Q$ de modo a ocorrerem apenas na forma $s^{\prime} p_{s}^{\prime} / Q$, que podem ser entendidas como um coeficiente de arrasto termodinâmico $\xi$ e assim as equações de movimento se resumem a

$$
\begin{aligned}
\dot{\mathbf{r}}_{i} & =\frac{\mathbf{p}_{i}}{m_{i}} \\
\dot{\mathbf{p}}_{i} & =-\frac{\partial V(\{\mathbf{r}\})}{\partial \mathbf{r}_{i}}-\xi \mathbf{p}_{i} \\
\dot{\xi} & =\frac{1}{Q}\left(\sum_{i=1}^{N} \frac{\mathbf{p}_{i}^{2}}{m_{i} s^{2}}-k_{B} T g\right) \\
\frac{\dot{s}}{s} & =\frac{\mathrm{d} \ln s}{\mathrm{~d} t}=\xi
\end{aligned}
$$

que podem ser eficientemente integradas 56 . 



\section{Referências Bibliográficas}

[1] Iijima, S. \& Ichihashi, T. Single-shell carbon nanotubes of 1-nm diameter. Nature 363, 603-605 (1993). 1, 11

[2] Baughman, R. H., Zakhidov, A. A. \& de Heer, W. A. Carbon nanotubesthe route toward applications. Science 297, 787-792 (2002). 1

[3] Demczyk, B. G. et al. Direct mechanical measurement of the tensile strength and elastic modulus of multiwalled carbon nanotubes. Materials Science and Engineering A 334, 173-178 (2002). 1

[4] Bachtold, A., Hadley, P., Nakanishi, T. \& Dekker, C. Logic circuits with carbon nanotube transistors. Science 294, 1317-1320 (2001). 1

[5] McEuen, P., Fuhrer, M. \& Park, H. Single-walled carbon nanotube electronics. IEEE Transactions on Nanotechnology 1, 78-85 (2002). 1

[6] Landi, B. J., Raffaelle, R. P., Castro, S. L. \& Bailey, S. G. Singlewall carbon nanotube-polymer solar cells. Progress in Photovoltaics: Research and Applications 13, 165-172 (2005). 1

[7] Endo, M., Kim, C., Nishimura, K., Fujino, T. \& Miyashita, K. Recent development of carbon materials for li ion batteries. Carbon 38, 183-197 (2000). 1

[8] Rather, S., Naik, M., Hwang, S. W., Kim, A. R. \& Nahm, K. S. Room temperature hydrogen uptake of carbon nanotubes promoted by silver metal catalyst. Journal of Alloys and Compounds 475, L17-L21 (2009).

1

[9] Lu, Y. et al. Room temperature methane detection using palladium loaded single-walled carbon nanotube sensors. Chemical Physics Letters 391, 344-348 (2004). 1 
[10] Male, K. B., Hrapovic, S., Liu, Y., Wang, D. \& Luong, J. H. T. Electrochemical detection of carbohydrates using copper nanoparticles and carbon nanotubes. Analytica Chimica Acta 516, 35-41 (2004). 1

[11] Novak, J. P. et al. Nerve agent detection using networks of single-walled carbon nanotubes. Applied Physics Letters 83, 4026-4028 (2003). 11

[12] Kam, N. W. S., O'Connell, M., Wisdom, J. A. \& Dai, H. Carbon nanotubes as multifunctional biological transporters and near-infrared agents for selective cancer cell destruction. Proceedings of the National Academy of Sciences of the United States of America 102, 11600-11605 (2005). 1

[13] Dai, H., Hafner, J. H., Rinzler, A. G., Colbert, D. T. \& Smalley, R. E. Nanotubes as nanoprobes in scanning probe microscopy. Nature $\mathbf{3 8 4}$, 147-150 (1996). [1

[14] Kim, S., Lee, H. W. \& Kim, S. Transplanting assembly of carbonnanotube-tipped atomic force microscope probes. Applied Physics Letters 94, 193102-3 (2009).

[15] Wilson, N. R. \& Macpherson, J. V. Carbon nanotube tips for atomic force microscopy. Nature Nanotech. 4, 483 - 491 (2009). 1

[16] Saito, R., Dresselhaus, G. \& Dresselhaus, M. S. Physical properties of carbon nanotubes (Imperial College Press, London, 1998). 1, 5, 8, 9, 11, 12, 13, 14, 18, 35,

[17] Hersam, M. C. Progress towards monodisperse single-walled carbon nanotubes. Nature Nanotech. 3, 387-394 (2008). 1, 15

[18] Arnold, M. S., Green, A. A., Hulvat, J. F., Stupp, S. I. \& Hersam, M. C. Sorting carbon nanotubes by electronic structure using density differentiation. Nature Nanotech. 1, 60-65 (2006). 2, 3, 14, 15, 22, 40. 41

[19] Rinzler, A. G. Materials processing: Sorting out carbon nanotube electronics. Nature Nanotech. 1, 17-18 (2006). 2, 15, 41

[20] Saslow, W., Bergstresser, T. K. \& Cohen, M. L. Band structure and optical properties of diamond. Phys. Rev. Lett. 16, 354-356 (1966). 8

[21] Wei, L., Kuo, P. K., Thomas, R. L., Anthony, T. R. \& Banholzer, W. F. Thermal conductivity of isotopically modified single crystal diamond. Phys. Rev. Lett. 70, 3764-3767 (1993). 8 
[22] Novoselov, K. S. et al. Two-dimensional atomic crystals. Proceedings of the National Academy of Sciences of the United States of America 102, 10451-10453 (2005). 8

[23] Geim, A. K. \& Novoselov, K. S. The rise of graphene. Nat Mater 6, 183-191 (2007). 8, 10,

[24] Geim, A. K. Graphene: Status and prospects. Science 324, 1530-1534 (2009). 8

[25] Lee, C., Wei, X., Kysar, J. W. \& Hone, J. Measurement of the elastic properties and intrinsic strength of monolayer graphene. Science $\mathbf{3 2 1}$, 385-388 (2008). 8

[26] Neto, A. H. C., Guinea, F., Peres, N. M. R., Novoselov, K. S. \& Geim, A. K. The electronic properties of graphene. Reviews of Modern Physics 81, 109 (2009). URL http://link .aps .org/abstract/RMP/v81/p109. 8. 9

[27] Ashcroft, N. W. \& Mermin, N. D. Solid state physics (Holt Rinehart and Winston, New York, 1976). 9

[28] Kroto, H. W., Heath, J. R., O’Brien, S. C., Curl, R. F. \& Smalley, R. E. C60: Buckminsterfullerene. Nature 318, 162-163 (1985). 10, 11

[29] Dresselhaus, M. S., Dresselhaus, G. \& Elkund, P. C. Science of fullerenes and carbon nanotubes (Academic Press, San Diego, 1996). 10

[30] Mehring, M., Scherer, W. \& Weidinger, A. Pseudoentanglement of spin states in the multilevel N15@C60 system. Physical Review Letters 93, 206603 (2004). 10

[31] Xie, R. et al. Tailorable acceptor C60-nBn and donor C60-mNm pairs for molecular electronics. Physical Review Letters 90, 206602 (2003). Copyright (C) 2009 The American Physical Society; Please report any problems to prola@aps.org. 10

[32] Schultz, D., Droppa, R., Alvarez, F. \& dos Santos, M. C. Stability of small Carbon-Nitride heterofullerenes. Physical Review Letters 90 (2003).

[33] Viani, L. \& dos Santos, M. Comparative study of lower fullerenes doped with boron and nitrogen. Solid State Communications 138, 498-501 (2006). 10 
[34] Hata, K. et al. Water-Assisted highly efficient synthesis of Impurity-Free Single-Walled carbon nanotubes. Science 306, 1362-1364 (2004). 11

[35] Iijima, S. Helical microtubules of graphitic carbon. Nature 354, 56-58 (1991).

[36] Monthioux, M. \& Kuznetsov, V. L. Who should be given the credit for the discovery of carbon nanotubes? Carbon 44, 1621-1623 (2006). 11

[37] Resasco, D. et al. A scalable process for production of single-walled carbon nanotubes (SWNTs) by catalytic disproportionation of $\mathrm{CO}$ on a solid catalyst. Journal of Nanoparticle Research 4, 131-136 (2002). 14

[38] Wenseleers, W., Cambré, S., Čulin, J., Bouwen, A. \& Goovaerts, E. Effect of water filling on the electronic and vibrational resonances of carbon nanotubes: Characterizing tube opening by raman spectroscopy. Advanced Materials 19, 2274-2278 (2007). 15, 22

[39] Tummala, N. R. \& Striolo, A. SDS surfactants on carbon nanotubes: Aggregate morphology. ACS Nano 3, 595-602 (2009). 15

[40] Accelrys, Inc, 9685 Scranton Rd., San Diego, CA 92121, U.S.A. Cerius ${ }^{2}$, Version 4.10. URL http://www .accelrys.com. 17

[41] Dauber-Osguthorpe, P. et al. Structure and energetics of ligand binding to proteins: Escherichia coli dihydrofolate reductase-trimethoprim, a drug-receptor system. Proteins: Structure, Function and Genetics 4, 31-47 (1988). And references therein. 17

[42] Tsusuki, S., Honda, K., Uchimaru, T. \& Mikami, S. High-level ab initio computations of structures and interaction energies of naphthalene dimers: Origin of attraction and its directionality. Journal of Chemical Physics 120, 647-659 (2003). 18

[43] Walsh, T. R. An ab initio study of the low energy surfaces of the naphtalene dimer. Chemical Physics Letters 363, 45-51 (2002). 18

[44] Hobza, P., Kabeláč, M., Šponer, J., Mejzlík, P. \& Vondrášek, J. Performance of empirical potentials (AMBER, CFF95, CVFF, CHARMM, OPLS, POLTEV), semiempirical quantum chemical methods (AM1, MNDO/ M, PM3), and ab initio Hartree-Fock method for interaction of DNA bases: Comparison with nonempirical beyond Hartree-Fock results. J. Comp. Chem. 18, 1136-1150 (1996). 18 
[45] Guillot, B. A reappraisal of what we have learnt during three decades of computer simulations on water. J. Mol. Liq. 101, 219-260 (2002). 18

[46] Rappé, A. K. \& Goddard III, W. A. Charge equilibration for moleculardynamics simulations. J. Phys. Chem. 95, 3358-3363 (1991). 18

[47] Hoover, W. G. Canonical dynamics: Equilibrium phase-space distributions. Phys. Rev. A 31, 1695-1697 (1985). 18, 53

[48] Head-Gordon, T. \& Hura, G. Water structure from scattering experiments and simulation. Chem. Rev. 102, 2651-2670 (2002). 19

[49] Mallik, A., Lee, S., Tran, L. \& Lobkovsky, E. Crystal topology prediction in alternating amphiphiles: Aromatic polyethers and the role of volume fraction. Crystal Growth \& Design 3, 467-473 (2003). 22

[50] Hennrich, F. et al. Diameter sorting of carbon nanotubes by gradient centrifugation: role of endohedral water. Phys. Stat. Sol. 244, 38963900 (2007). 23, 33, 38,

[51] Koga, K., Gao, G. T., Tanaka, H. \& Zeng, X. C. Formation of ordered ice nanotubes inside carbon nanotubes. Nature 412, 802-805 (2001). 23,33

[52] Arnold, M. S., Suntivich, J., Stupp, S. I. \& Hersam, M. C. Hydrodynamic characterization of surfactant encapsulated carbon nanotubes using an analytical ultracentrifuge. ACS Nano 2, 2291-2300 (2008). 39

[53] Levine, I. Quantum chemistry (Prentice Hall, Englewood Cliffs N.J., 1991), 4th ed. edn. 43

[54] Accelrys, Inc. Cerius ${ }^{2}$ manual. URL http://www.chem.cmu.edu/ courses/09-560/docs/msi/ffbsim/FF_SimulTOC.doc.html. Online, acessado em 02/06/2009. 45, 46, 48, 49, 51, 53

[55] Simulations, B. Cerius ${ }^{2}$ Simulation Tools User's Reference (Accelrys, Inc, 9685 Scranton Rd., San Diego, CA 92121, U.S.A., 1995). 47

[56] Frenkel, D. \& Smit, B. Understanding molecular simulation: from algorithms to applications (Academic Press, San Diego, 1996). 52, 53, 54, 55

[57] U.S. Information Agency. Children playing leap frog in a Harlem street (ca. 1930). URL http://arcweb.archives.gov/. Online, acessado em 02/06/2009. 52 
[58] Allen, M. P. \& Tildesley, D. J. Computer simulation of liquids (Oxford University Press, Oxford, 1989). 52, 53

[59] Berendsen, H. J. C., Postma, J. P. M., van Gunsteren, W. F., DiNola, A. \& Haak, J. R. Molecular dynamics with coupling to an external bath. The Journal of Chemical Physics 81, 3684-3690 (1984). 53 